\title{
Study on the Early Warning and Forecasting of Flash Floods in Small Watersheds Based on the Rainfall Pattern of Risk Probability Combination
}

Lu Lu

Zhengzhou University

Wenlin Yuan

Zhengzhou University

Chengguo Su ( $\sim$ suchguo@163.com )

Zhengzhou University https://orcid.org/0000-0001-8578-3494

Qianyu Gao

Hohai University

Denghua Yan

China Institute of Water Resources and Hydropower Research

\section{Zening Wu}

Zhengzhou University

Original research

Keywords: Flash floods, copula function, rainfall pattern of risk probability, critical rainfall, early warning mode

Posted Date: February 5th, 2021

DOl: https://doi.org/10.21203/rs.3.rs-166922/v1

License: (9) This work is licensed under a Creative Commons Attribution 4.0 International License.

Read Full License

Version of Record: A version of this preprint was published at Stochastic Environmental Research and Risk Assessment on July 14th, 2021. See the published version at https://doi.org/10.1007/s00477-02102059-0. 


\section{Study on the Early Warning and Forecasting of Flash Floods in Small} Watersheds Based on the Rainfall Pattern of Risk Probability

\section{Combination}

(1)

Lu Lu ${ }^{\mathrm{a}}$, Wenlin Yuan ${ }^{\mathrm{a}}$, Chengguo Su${ }^{\mathrm{a}^{*}}$, Qianyu $\mathrm{Gao}^{\mathrm{b}}$, Denghua Yan ${ }^{\mathrm{a}, \mathrm{c}}$, Zening $\mathrm{Wu}^{\mathrm{a}}$

a. School of Water Conservancy Engineering, Zhengzhou University, Zhengzhou, 450001, China.

b. College of Hydrology and Water Resources, Hohai University, Nanjing 210098, China.

c. Water Resources Department, China Institute of Water Resources and Hydropower Research, Beijing, 100038,

China.

E-mail address: lulu2015@zzu.edu.cn (Lu Lu),suchguo@163.com (corresponding author, Chengguo Su)

Authors' contributions: All authors contributed to the study conception and design. Methodology,

Writing - Review \& Editing were performed by Lu Lu. Software, Writing - Original Draft, Validation, Funding acquisition were performed by Wenlin Yuan. Conceptualization, Supervision, Project administration, Writing - Review \& Editing were performed by Chengguo Su. Investigation was performed by Qianyu Gao. Data Curation was performed by Denghua Yan. Formal analysis was performed by Zening $\mathrm{Wu}$.

Abstract: Flash floods cause great harm to people's life and property safety. Rainfall is one of the main causes of flash floods in small watersheds. The uncertainty of rainfall events results in inconsistency between the traditional single rainfall pattern and the actual rainfall process, which poses a great challenge for the early warning and forecasting of flash floods. This paper proposes a novel rainfall pattern based on total rainfall and peak rainfall intensity, i.e., the rainfall pattern of risk probability combination (RPRPC). To determine the joint distribution function with the best fitting effect, copula functions are introduced and optimized. On this basis, the HEC-HMS 
hydrological model is used to simulate the rainfall-runoff process, a trial algorithm is used to calculate the critical rainfall (CR), and an optimistic-general-pessimistic (O-G-P) early warning mode considering the decision maker's risk preference is proposed. The small watershed of Xinxian in Henan province, China, is taken as a case study for calculation. The results show that the RPRPC is feasible and closer to the actual rainfall process than the traditional rainfall pattern (TRP) and that the HEC-HMS model can be applied to small watersheds in hilly areas. Additionally, the influence of antecedent soil moisture condition (ASMC) and rainfall pattern on critical rainfall varies with the change of peak rainfall intensity and rainfall duration. Finally, the O-G-P early warning mode is effective and provides a valuable reference for the early warning and forecasting of flash floods in small watersheds in hilly areas.

Keywords: Flash floods $\cdot$ copula function $\cdot$ rainfall pattern of risk probability $\cdot$ critical rainfall $\cdot$ early warning mode

\section{Introduction}

Flash floods refer to a sudden rise of the water level (within a few hours or less) together with a significant peak discharge which are caused by heavy rainfall (Braud et al. 2014). In China, flash floods generally refer to brief, intense surface runoff caused by short-term heavy rainfall in small, hilly watersheds below several hundred square kilometers, with a response time of a few hours or less. With global climate change, extreme rainfall events occur frequently, and flash floods have become one of the most significant natural hazards (Morin et al. 2009; Han et al. 2015; Hosseini et al. 2020), causing the greatest loss of human life and economic damage (Karbasi et al. 2018; Gaume et al. 2009). According to statistics taken over many years, the casualties of China's flash floods 
account for approximately $70 \%$ of the casualties of flood disasters (Ministry of Water Resources, P.R.C. 2020). Hence it is necessary to carry out high-accuracy early warning and prediction of flash floods for disaster prevention and damage reduction.

Several indicators have been used to evaluate the susceptibility and severity of flash floods, such as the flash-flood potential index (FFPI) (Smith 2003), flashiness (Saharia et al. 2017) and critical rainfall (CR) (Kuo et al. 2018). Of these indexes, CR is the most widely used in the early warning of flash floods (Hapuarachchi et al. 2011; Kong et al. 2020), therefore, its accurate determination is key (Norbiato et al. 2009). Statistical induction based on data-driven methods, and the hydrology and hydraulics method (HHM), which is based on hydrology theory, are commonly used methods to calculate CR (Liu 2019). However, the physical mechanism involved in the occurrence for flash floods is ignored in statistical induction, so the CR obtained in most cases cannot be directly applied (Chen 2013). Therefore, HHM is adopted in the current early warning and forecasting of flash floods. The flash flood guidance (FFG), developed by the American Hydrological Research Center, is widely used in the USA (Norbiato et al. 2009). Based on FFG, many studies have improved CR accuracy from the perspective of hydrological models for simulating rainfall-runoff processes (Seo et al. 2013; Clark et al. 2014). This indicates that the hydrological model based on the rainfall-runoff process has become an important part of CR calculation.

The hydrological model can well consider the meteorological environment and hydrological characteristics of the watershed and reflect the rainfall-runoff process. Many hydrologic models have been applied to simulate and forecast flash flood processes (Adamovic et al. 2016; Zhang et al. 2019). Ivanescu and Drobot (2016) used a hydrological-hydraulic model which coupled MIKE 
SHE with MIKE 11 to determine the rainfall thresholds and transformation coefficients from hourly rainfall to other durations in the early warning of flash floods. Douinot et al. (2016) assessed the applicability of the FFG method on French Mediterranean catchments using the MARINE hydrological model. These hydrological models take into account the hydrometeorological and watershed characteristics of the study area, which can well simulate the hydrological process when flash floods occur. Rainfall is an important factor affecting the accuracy of hydrological models in flood simulation (Diederen and Liu 2020; Klongvessa et al. 2018). Due to the randomness of rainfall, its distribution in time and space is not uniform, which has a great impact on hydrological simulation. Carreau et al. (2016) used daily data from eight rain gauge stations in the Gardon River catchment in Anduze, France, to make an accurate characterization of the spatial variability of flood-risk rainfall. Zoccatelli et al. (2010) used a spatial rainfall metric to clarify the dependence between spatial rainfall organization, basin morphology and runoff response. However, because the spatial scale of a small watershed in a mountainous or hilly area is small, only the time scale of rainfall is studied during the research process.

The change in rainfall over time is called the rainfall pattern, which reflects the time distribution of rainfall events. The rainfall pattern has a great influence on the flood process (Máca and Torfs 2009; Tao et al. 2017). Since the 1940s, many rainfall patterns have been proposed, such as model rainfall patterns (Yuan et al. 2019a), the Chicago rainfall pattern (Keifer and Chu 1957) and the P\&C rainfall pattern (Pilgrim and Cordery 1975), which are applied in the calculation of urban floods. With the development of modern hydrology theory, the study of rainfall pattern has been rapidly developed. Forestieri et al. (2016) calculated and analyzed the flood processes of different designed rainstorm patterns in the Sicilian basin, and obtained an early warning mechanism 
which was suitable for different rainfall patterns. Pedrozo-Acuna et al. (2017) analyzed and studied the flash floods caused by different rainfall patterns in Tabasco, Mexico, and established an early warning and forecasting response mechanism for these different rainfall patterns. Hou et al. (2017) uncovered the quantitative relationship between rainfall pattern and the degree of waterlogging by simulating the waterlogging process under different rainstorm conditions with different recurrence periods and peak ratio. Yuan et al. (2019b) proposed four rainfall patterns based on the different rain peak positions in a designed rainfall pattern to calculate CR. Park and Chung (2020) proposed three-day rainfall patterns to better reproduce the characteristics of rainfall events. Although the above studies enrich the study of rainfall patterns, most of them adopt fixed rainfall patterns. Moreover, these studies seldom considered the uncertainty of the temporal distribution in rainfall events. They also ignored the influence of the uncertainty of the characteristic parameters of rainfall in the calculation of runoff yield and conflux for a watershed. With the intensification of climate change, the sudden frequency of rainfall events increases, which intensifies the uncertainty of the rainfall pattern. Therefore, the uncertainty of rainfall pattern in small watersheds must be considered in the early warning and forecasting of flash floods. Furthermore, most of the above rainfall pattern studies are applicable to urban areas, but few are applicable to small watersheds in the mountainous and hilly areas.

In view of the mentioned operational hydrology problems with the early warning and forecasting of flash floods, a novel design method for the rainfall pattern of risk probability combination (RPRPC) is proposed in this paper. Combined with the HEC-HMS hydrological model, this method is applied to flash floods early warning and forecasting. The main contributions of this paper can be summarized as follows: 
(1) A novel rainfall pattern design method based on risk probability combination is proposed,

111 which takes into account the uncertainty of rainfall events. In this method, the uncertainty of rainfall

112 is considered through a probability analysis of rainfall characteristic parameters, and copula theory

113 is used to construct the joint distribution function of rainfall characteristic parameters.

114 (2) Based on the RPRPC, the HEC-HMS model is used to simulate the rainfall-runoff process in a small watershed, and the trial algorithm is used to calculate the CR threshold space in a multiscenario mode.

(3) Based on the current flood control capacity and CR threshold space of disaster prevention objects, an effective early warning mode including optimistic, general, and pessimistic (O-G-P) forecasting of flash floods is established. This early warning mode considers the disaster prevention early warning and forecasting flash floods in small watersheds. analysis are shown in Section 4. Finally, Section 5 outlines the conclusions of the study.

\section{Methodology}

In this section, the design method of the RPRPC, the CR calculation method based on the HECHMS model, and the flash flood early warning mode are described in detail. It should be noted that this study only focuses on unimodal rainfall. The overall process diagram of this study is shown in Fig. 1. 

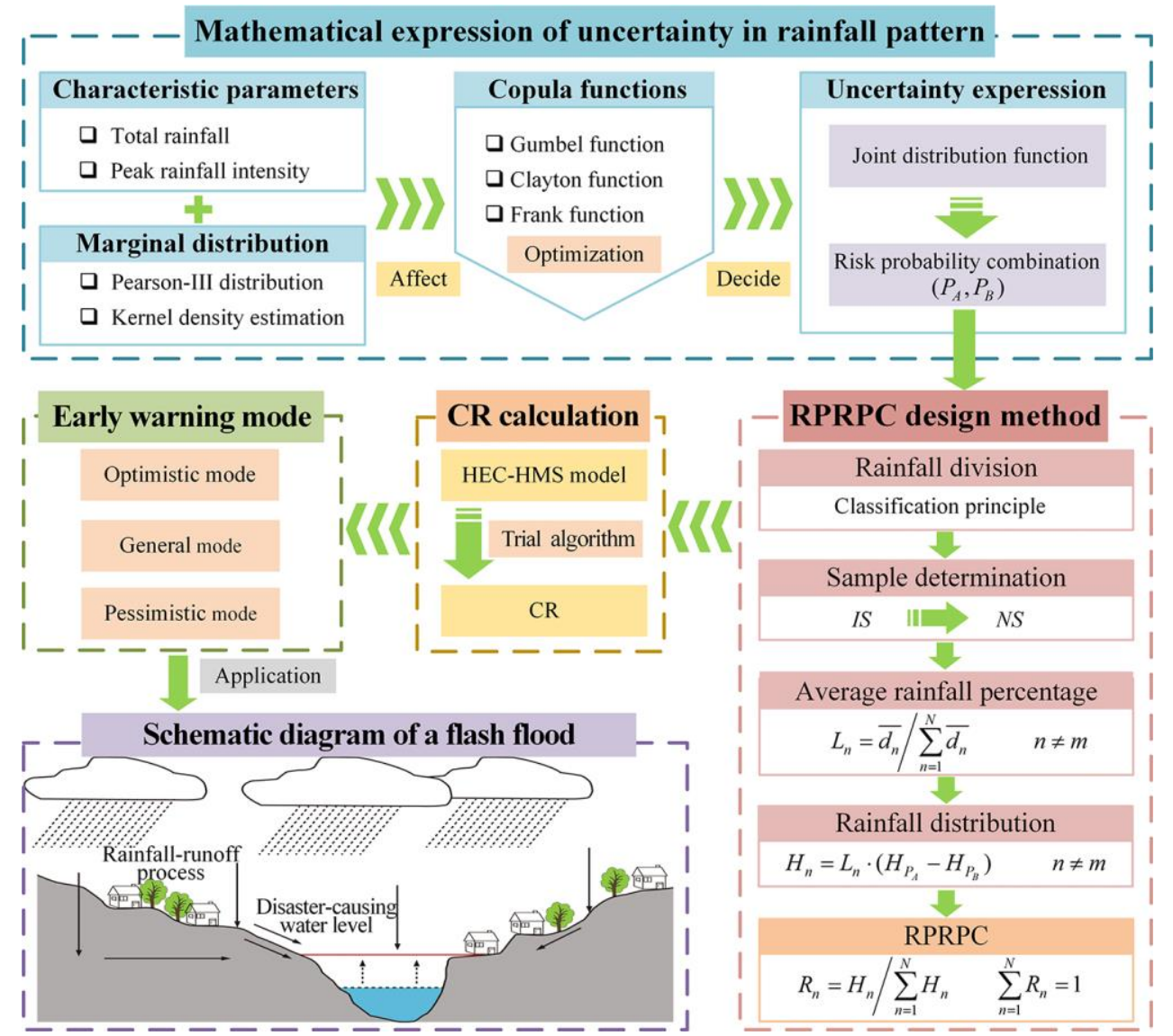

Fig.1 Schematic diagram of flash flood early warning and forecasting based on the RPRPC

\subsection{Design method for the rainfall pattern of risk probability combination}

\subsubsection{The definition of rainfall pattern of risk probability combination}

Risk probability combination is the basis of the design method for the RPRPC, hence the definition of risk probability combination will be introduced first. For rainfall events, rainfall characteristic parameters can quantitatively describe the rainfall time distribution characteristic.

Based on the feature extraction and analysis from the actual rainfall process, total rainfall and peak rainfall intensity are implemented to describe the rainfall characteristics (Marc et al. 2020; Palynchuk and Guo 2011). The total rainfall indicates the sum of rainfall for each time period, and the peak rainfall intensity refers to the maximum rainfall over all time periods. Based on the 
probability analysis of total rainfall and peak rainfall intensity, when the peak rainfall intensity exceeds a value corresponding to a certain probability $P_{B}$ and when the total rainfall exceeds a value corresponding to a probability $P_{A}$, the risk probability combination can be defined as $\left(P_{A}, P_{B}\right)$. Hence the risk probability is treated as a conditional probability, as shown in Eq. (1). The rainfall pattern corresponding to $\left(P_{A}, P_{B}\right)$ is called the rainfall pattern of risk probability combination (RPRPC), as shown in Eq. (2).

$$
\begin{gathered}
F_{y \mid x_{P_{A}}}(X, Y)=P\left(Y \geq y \mid X \geq x_{P_{A}}\right)=\frac{1-F_{Y}(y)-F_{X}\left(x_{P_{A}}\right)+F\left(x_{P_{A}}, y\right)}{1-F_{X}\left(x_{P_{A}}\right)} \\
\left(P_{A}, P_{B}\right)=\left(P\left(X \geq x_{P_{A}}\right), P\left(Y \geq y \mid X \geq x_{P_{A}}\right)\right)
\end{gathered}
$$

Where $X$ and $Y$ denote the total rainfall and the peak rainfall intensity, respectively. $x_{P_{A}}$ denotes the total rainfall corresponding to $P_{A} \cdot F_{X}(x), F_{Y}(y)$ and $F(x, y)$ are the distribution functions of total rainfall, the distribution function of peak rainfall intensity, and the joint distribution function of total rainfall and peak rainfall intensity, respectively. These distribution functions will be discussed in detail in the next section.

\subsubsection{Copula function optimization}

In the previous section, the determination of the joint distribution function is an important part of the RPRPC calculation. Copula functions have the ability to connect different marginal distribution functions together (Kao and Govindaraju 2010; Thong et al. 2019). However, there are many kinds of copula functions, and different copula functions have different fitting effects. Therefore, copula functions must be optimized. Copula function optimization steps are shown below.

(1) In this research, the Pearson-III distribution was used to fit the total rainfall. Nonparametric 
kernel density estimation was adopted to determine the distribution of peak rainfall intensity. The Kolmogorov-Smirnov (K-S) test method was used to test the marginal distribution functions of total rainfall and peak rainfall intensity.

(2) Three correlation coefficients, including the Pearson linear correlation coefficient $\gamma$, Kendall rank correlation coefficient $\tau$, and Spearman rank correlation coefficient $\rho$, were selected to analyze the correlation between the total rainfall and the peak rainfall intensity.

(3) The copula function parameters (i.e., Gumbel, Clayton and Frank) were estimated using the correlation index method, and the fitting quality of the joint distribution function was tested using the K-S test.

(4) The goodness of fitting for the three copula functions was evaluated by Root Mean Square Error (RMSE), Akaike Information Criterions (AIC) and Bayesian Information Criterions (BIC). Then, the copula function with the best fitting quality was selected as the joint distribution function.

\subsubsection{Rainfall distribution for each time period}

According to the optimal copula function in Section 2.1.2, the total rainfall and peak rainfall intensity can be determined using risk probability combination. Then, the rainfall distribution process for a rainfall event can be obtained, and the specific steps are as follows, and summarized in Fig. 2. 


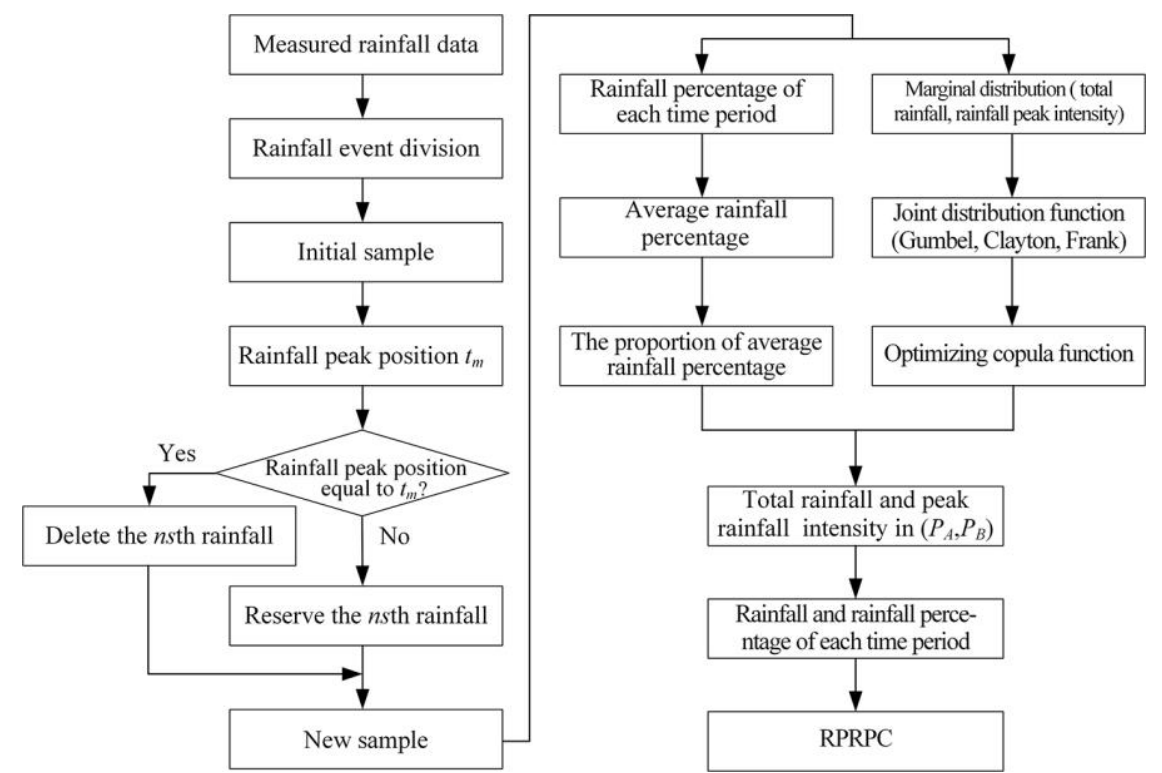

Fig.2 Calculation flow chart for the rainfall distribution for each time period

(1) Collect the rainfall data for the study area, and classify the actual rainfall data according to the classification principle of rainfall events (Yuan et al. 2019a).

(2) Select the rainfall events with a total duration $N$ as the initial sample $I S$.

(3) Take the time period with the most occurrences of rainfall peak counted from IS as the rainfall peak position of the RPRPC $t_{m}$ in the study area. Then, select the rainfall events whose rainfall peak position is equal to $t_{m}$ in the actual rainfall data as the new sample NS.

(4) Calculate the rainfall percentage $d_{n, n s}$ of each time period for each rainfall in NS. Then the average rainfall percentage $\overline{d_{n}}$ of each time period outside $t_{m}$ can be obtained, as shown in Eq. (3).

$$
\overline{d_{n}}=\left(d_{n, 1}+d_{n, 2}+\mathrm{L} d_{n, n s}+\mathrm{L}+d_{n, N S-1}+d_{n, N S}\right) / N S \quad(n \neq m)
$$

(5) Take the time periods outside $t_{m}$ as a whole and calculate the proportion for the average rainfall percentage in the sum of the average rainfall percentage $L_{n}$ according to Eq. (4).

$$
L_{n}=\overline{d_{n}} / \sum_{n=1}^{N} \overline{d_{n}} \quad n \neq m
$$

(6) Total rainfall $H_{P_{A}}$ and peak rainfall intensity $H_{P_{B}}$, with the risk probability combination $\left(P_{A}, P_{B}\right)$, can be calculated based on the copula function optimized in Section 2.1.2. 
(7) Calculate the rainfall of each time period outside $t_{m}$ based on $H_{P_{A}}, H_{P_{B}}$ and $L_{n}$, as

198 shown in Eq. (5). Then determine the rainfall percentage $R_{n}$ of each time period, including $t_{m}$ in

199 the RPRPC, as shown in Eq. (6)-(7).

$$
\begin{aligned}
& H_{n}=L_{n} \cdot\left(H_{P_{A}}-H_{P_{B}}\right) \quad n \neq m \\
& R_{n}=H_{n} / \sum_{n=1}^{N} H_{n} \quad n=1,2,3 \mathrm{~L} N \\
& \sum_{n=1}^{N} R_{n}=1
\end{aligned}
$$

\subsection{Simulation of flash floods based on the HEC-HMS hydrological model}

Considering the flexibility and applicability of the rainfall-runoff relationship, the HEC-HMS model was used to simulate the rainfall-runoff process in a small watershed (Laouacheria and Mansouri 2015). The HEC-HMS model is a distributed hydrological model, and has been developed by the United States Army Corps of Engineers' Hydrologic Engineering Center. In order to fully consider the uneven spatial distribution of rainfall and the complex underlying surface, the model is closely combined with GIS technology to divide the study area into several sub-basins based on the natural water separation lines, and the rainfall-runoff process is then simulated.

The HEC-HMS hydrological model is mainly composed of four modules: basin module, meteorological module, control specifications module and time-series data module. Of these modules, the basin module is the model generalization of the rainfall-runoff process, including rainfall loss, direct runoff, base flow and channel confluence. The function of the meteorological module is to analyze meteorological elements in the rainfall-runoff process. The control specifications module contains all of the time control information for the model. The time-series data module is mainly used to store rainfall, evaporation, runoff and other data. Each rainfall-runoff 
process simulation will call the above four modules. Details of the model structure and module invocation are given in the HEC-HMS Technical Reference Manual (USACE-HEC 2000). and watershed conditions, an appropriate combination of methods can be selected to calculate the the measured data in the study area. By comparing the measured and simulated values of the flood, the best simulation parameters are determined. The appropriate method combination selection process and parameter calibration process can be referred to in Ref. (Du et al. 2012; Zelelew and

\subsection{Critical Rainfall Calculation} chart of the trial algorithm is shown in Fig.3. The specific steps are summarized as follows.

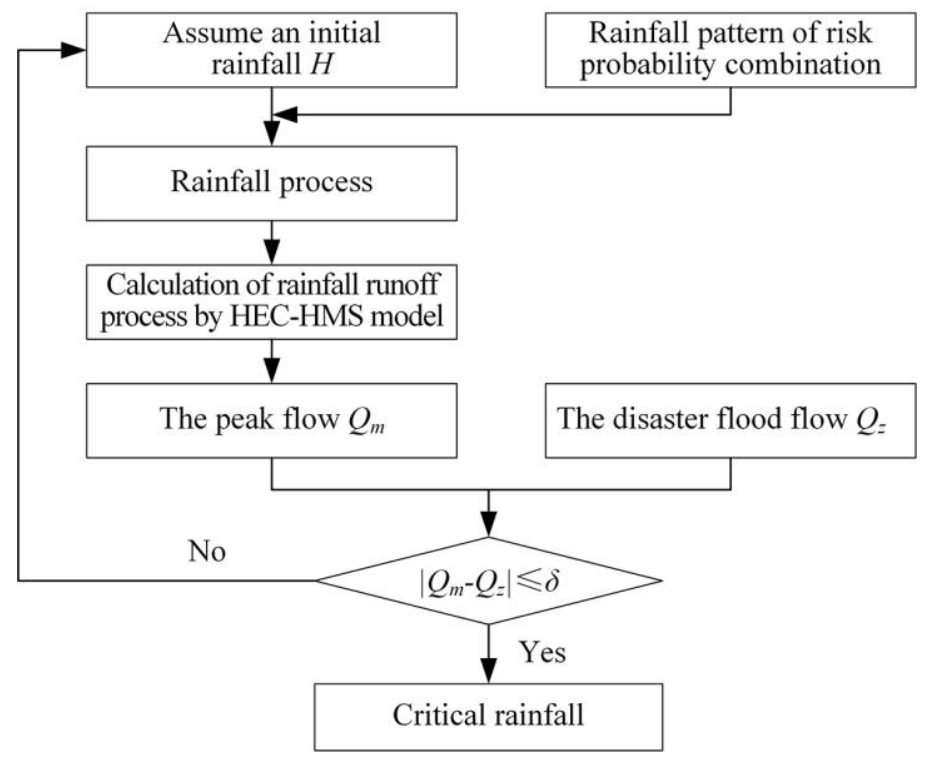

Fig.3 Flowchart of the trial algorithm for critical rainfall

(1) The HEC-HMS model is constructed using the method mentioned in Section 2.2. 
(2) Assuming an initial rainfall $R$, the rainfall of each time period in the RPRPC is input into the established HEC-HMS model to simulate the rainfall-runoff process. The peak flow $Q_{m}$ is then obtained.

(3) Through the analysis of the water level-flow relationship for the control channel in the study area, the disaster flood flow $Q_{z}$ is determined according to the measured disaster water level.

(4) $Q_{m}$ and $Q_{z}$ are compared. If the deviation satisfies the requirement of calculation accuracy (i.e., $\left|Q_{m}-Q_{z}\right| \leq \delta$ ), the trial calculation is finished. If the accuracy is not satisfied, adjust the assumed rainfall and repeat the trial calculation until the accuracy requirement is satisfied. At this point, $R$ is the critical rainfall.

\subsection{Optimistic-General-Pessimistic early warning mode}

Limited by rainfall uncertainty, if the uncertainty of the CR for flash floods is fully considered, the workload of the early warning process will be greatly increased. In order to reduce the complexity of the early warning process as much as possible and take into account the rainfall uncertainty, a risk preference early warning mode based on the RPRPC is proposed in this paper. The process of constructing the flash flood early warning mode can be summarized as the following steps.

(1) Based on an analysis of the current flood control capacity of the disaster prevention target, and assuming the same frequency for rainfall and flooding, the range of risk probability combination in the study area is determined. The rainfall pattern collection of the RPRPCs is then determined.

(2) The CR scatterplot is drawn for different combinations of early warning time periods (EWTP) and antecedent soil moisture condition (ASMC) in different RPRPCs. The points under the 
three-dimensional coordinates of the scatterplot are projected to two-dimensional coordinates. The early warning mode diagram for different risk preferences are then made, as shown in Fig. 4. In this early warning mode, the optimistic, general and pessimistic (O-G-P) modes are, respectively, the upper limit, the mean value and the lower limit of the CR threshold space.

(3) The appropriate early warning mode is selected based on the rainfall grades from authoritative numerical forecast information. Generally, the rainstorm grades are divided into rainstorm, heavy rainfall, and extraordinary heavy rainfall, which correspond to the optimistic, general and pessimistic modes, respectively.

(4) The ASMC is determined according to previous rainfall events. Early warning signals that remind people to evacuate immediately are then issued according to the sliding comparison between cumulative rainfall and CR in different EWTPs.
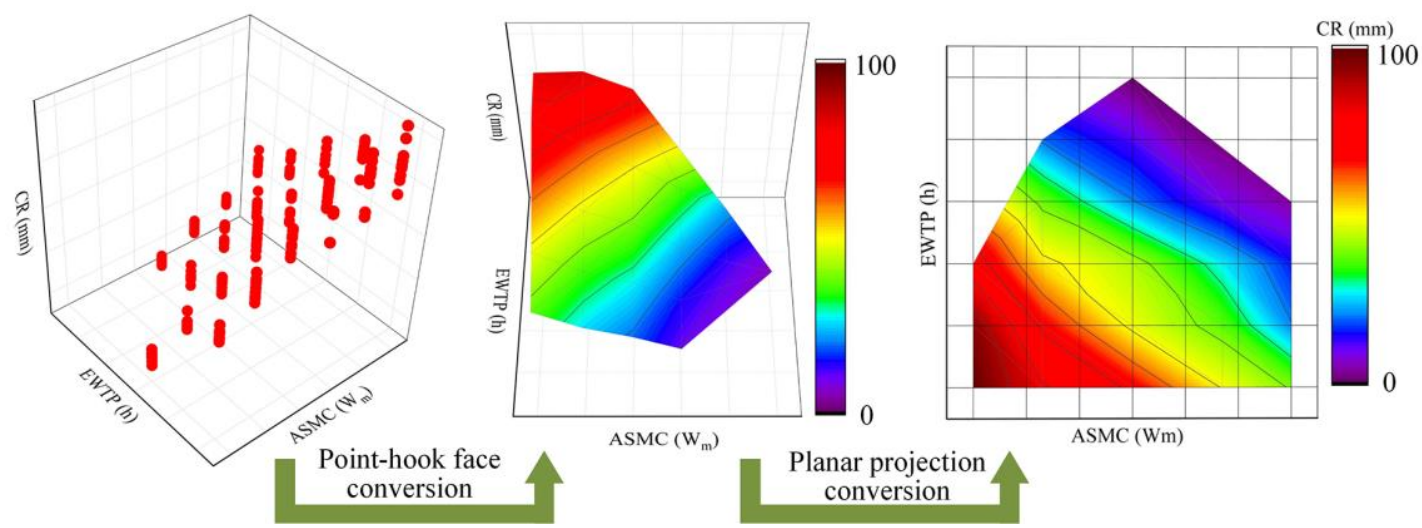

Fig. 4 Schematic diagram of early warning mode establishment

\section{Case Study}


274

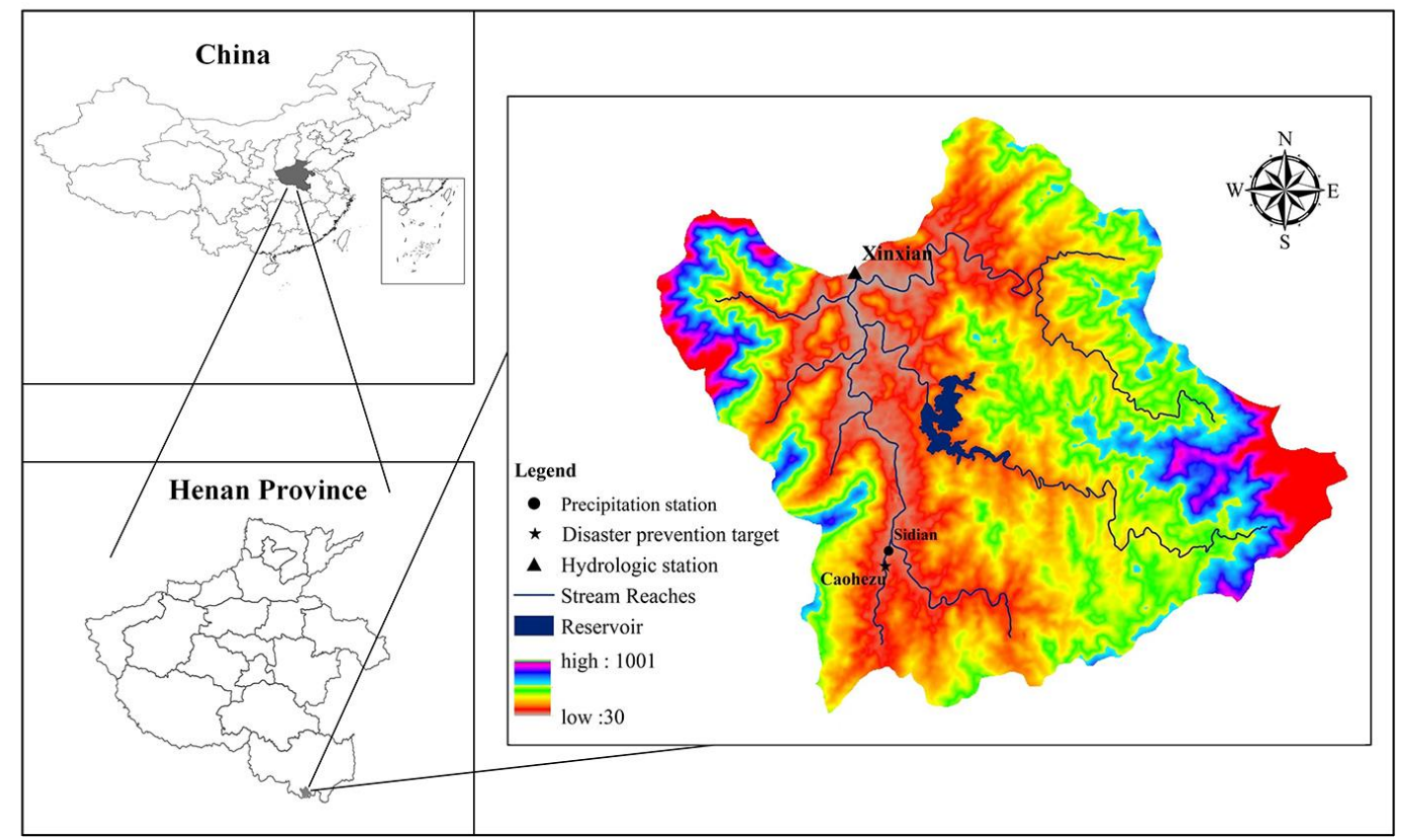

Fig. 5 Schematic diagram of the Xinxian watershed

Table 1 characteristics of the study area

\begin{tabular}{ccccccc}
\hline Watershed & $\begin{array}{c}\text { Area } \\
\left(\mathrm{km}^{2}\right)\end{array}$ & $\begin{array}{c}\text { River length } \\
(\mathrm{m})\end{array}$ & $\begin{array}{c}\text { Mean } \\
\text { slope }\end{array}$ & $\begin{array}{c}\text { Typical river } \\
\text { section }\end{array}$ & Source of flood date & Source of rainfall date \\
\hline \multirow{2}{*}{ Xinxian } & 274 & 39.27 & 0.018 & Caohezu & $\begin{array}{c}\text { Xinxian hydrology station } \\
(1967-2018)\end{array}$ & $\begin{array}{c}\text { Sidian rainfall station } \\
(1968-2018)\end{array}$
\end{tabular}

The data used in this paper includes GIS data, rainfall data and flood data. The GIS data, including the digital elevation model, land use and soil maps were collected from the National Geomatics Center of China. The measured rainfall data and flood data were provided by the hydrological bureau of Henan. The time resolution was considered as $1 \mathrm{~h}$. After the division of rainfall events, there were 44 rainfall events with a total duration of $12 \mathrm{~h}$, which accounted for the largest proportion of the total rainfall events. 


\section{Results and Discussion}

\subsection{Joint Distribution Function Optimization}

In this paper, the Pearson-III distribution and the kernel density estimation method have been selected to determine the marginal distribution of total rainfall and peak rainfall intensity, respectively. The rationality of the selected marginal distribution function was verified by K-S test. The fitting quality of these two marginal distribution functions was evaluated, and the correlations between total rainfall and peak rainfall intensity were analyzed. The results are shown in Table 2 and Table 3.

Table 2 The results of K-S test for marginal distribution

\begin{tabular}{|c|c|c|c|c|}
\hline \multirow{2}{*}{ Characteristic parameters } & \multicolumn{4}{|c|}{$\mathrm{K}-\mathrm{S}$ test } \\
\hline & \multicolumn{3}{|c|}{ Calculated } & Critical value \\
\hline Total rainfall & \multicolumn{3}{|c|}{0.106} & \multirow{2}{*}{0.2006} \\
\hline Peak rainfall intensity & \multicolumn{3}{|c|}{0.114} & \\
\hline \multirow{2}{*}{ Characteristic parameters } & \multicolumn{4}{|c|}{ Correlation coefficients } \\
\hline & $\gamma$ & $\tau$ & $\rho$ & Reference value \\
\hline $\begin{array}{c}\text { Total rainfall } \\
\text { Peak rainfall intensity }\end{array}$ & 0.822 & 0.806 & 0.876 & 0.8 \\
\hline
\end{tabular}

The significance level of the K-S test was set as $\alpha=0.05$. When $n=44$, the corresponding critical value was 0.2006 . The K-S test results of both the total rainfall and peak rainfall intensity were both smaller than the critical value. These results indicate that the Pearson-III distribution and the kernel density estimation method are feasible for simulating the marginal distribution of total rainfall and peak rainfall intensity, respectively. According to the correlation results, all correlation coefficients, including Pearson linear correlation coefficient $\gamma$, Kendall rank correlation coefficient $\tau$, and Spearman rank correlation coefficient $\rho$, were greater than reference value 0.8 , which signifies a strong positive correlation between the total rainfall and peak rainfall intensity. Therefore, the copula function can be used to construct the joint distribution function of the total rainfall and peak rainfall intensity. 

best copula function. The rationality of the three copula functions was verified by K-S test, and the goodness of fit of the three copula functions were evaluated by RMSE, AIC and BIC Criterion. The results are shown in Table 4 and Table 5. evaluation values of the Frank function were the smallest for the three evaluation criterions of fitting goodness, which shows that the goodness of fit of the Frank function was the best. Therefore, the Frank function was selected as the joint distribution function.

\subsection{Hydrological Model Application Assessment}

Based on the digital elevation data of the study area, the HEC-HMS model was established calculation of the basin module. These included the initial and constant method, the soil conservation service unit hydrography method, the recession curve method and the Muskingum method. Ten typical floods were selected from the watershed, in which seven floods were used for 
parameter calibration and three floods were used for verification. The results are shown in Table 6.

\begin{tabular}{|c|c|c|c|c|c|c|}
\hline \multirow{2}{*}{ State } & \multirow{2}{*}{ Number } & \multicolumn{2}{|c|}{ Peak flow $\left(\mathrm{m}^{3} / \mathrm{s}\right)$} & \multicolumn{2}{|c|}{ Flood volume $\left(10^{6} \mathrm{~m}^{3}\right)$} & \multirow{2}{*}{ NSE } \\
\hline & & Simulated & Measured & Simulated & Measured & \\
\hline \multirow{7}{*}{ Calibration } & 19820719 & 766.0 & 761.0 & 33.4 & 28.8 & 0.933 \\
\hline & 19870705 & 1007.8 & 1060.0 & 47.7 & 40.3 & 0.860 \\
\hline & 19910703 & 822.8 & 980.0 & 43.9 & 47.4 & 0.922 \\
\hline & 19990627 & 301.4 & 309.0 & 13.5 & 15.6 & 0.883 \\
\hline & 20030708 & 550.8 & 539.0 & 24.5 & 25.3 & 0.939 \\
\hline & 20080816 & 759.9 & 749.0 & 41.2 & 39.3 & 0.801 \\
\hline & 20130526 & 170.0 & 166.0 & 7.9 & 8.3 & 0.923 \\
\hline \multirow{3}{*}{ Validation } & 19850713 & 209.3 & 191 & 5.8 & 5.4 & 0.861 \\
\hline & 19960714 & 966.1 & 935 & 30.9 & 29.6 & 0.926 \\
\hline & 20040718 & 347 & 339 & 2.8 & 2.9 & 0.887 \\
\hline
\end{tabular}

\subsection{Rationality Analysis of the RPRPC} corresponding risk probability combination was determined through the Frank copula function. 

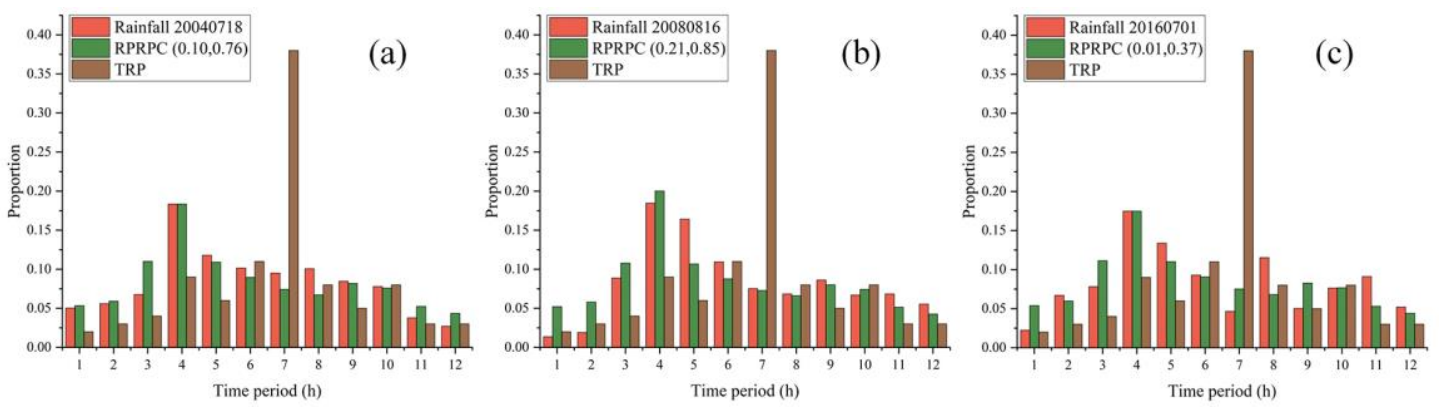

Fig.6 Comparison of rainfall patterns:(a) rainfall 20040718 (b) rainfall 20080816 (c) rainfall 20160701

It can be seen that the differences between the TRP and measured rainfall are very large,

especially for the rainfall peak position and peak rainfall intensity. The reason for this is that, in the

calculation of the TRP, the rainfall peak position was set backward and the peak rainfall intensity is

set high based on the consideration of engineering safety. Compared to the TRP, the RPRPC is

obviously less different to the measured rainfall. The three RPRPCs all have the same rainfall peak

positions as the measured rainfall, and the peak rainfall intensity differs by very little. Besides, all

three RPRPCs have a single rainfall peak with a forward rainfall peak position, which is the same

as the corresponding measured rainfall. Therefore, the RPRPC has the characteristic of maintaining trend consistency with the measured rainfall.

\section{(1) Approach degree analysis}

The approach degree (Liu et al. 2019), which is commonly used in rainfall pattern research to shown in Table 7.

$$
e=1-\sqrt{\frac{1}{N} \cdot \sum_{n=1}^{N}\left(z_{n}-y_{n}\right)^{2}}
$$

Where $e$ is the approach degree, $N$ is the total number of time periods; $Z_{n}$ is the rainfall proportion 
of the $n$th time period for the measured rainfall; $y_{n}$ is the rainfall proportion of the $n$th time period

358 for the RPRPC.

Table 7 Approach degree of three rainfall events

\begin{tabular}{cccc}
\hline Rainfall number & 20040718 & 20080816 & 20160701 \\
\hline Approach degree & 0.981 & 0.951 & 0.966 \\
\hline
\end{tabular}

It can be seen that the approach degrees between the RPRPC and measured rainfall are all greater than 0.95 , indicating that the RPRPC is in good agreement with the measured rainfall. This also proves the rationality of the RPRPC to a certain extent.

\section{(2) CR analysis}

The CR for different EWTPs is calculated in this section based on the RPRPC. Moreover, CR is compared with time-interval characteristic rainfall (TICR) (Park and Chung, 2020) . and the deviation degree (National Mountain Flood Prevention and Control Group, 2016) has also been calculated according to Eq (9). The results are shown in Table 8.

$$
D D=|(C R-T I C R) / T I C R| \times 100 \%
$$

Where DD is the deviation degree.

Table 8 Deviation degree results between CR and TICR

\begin{tabular}{cccccc}
\hline $\begin{array}{c}\text { Rainfall } \\
\text { number }\end{array}$ & $\begin{array}{c}\text { ASMC } \\
(\mathrm{mm})\end{array}$ & $\begin{array}{c}\text { Early-warning } \\
\text { Time(h) }\end{array}$ & TICR (mm) & CR (mm) & DD (\%) \\
\hline \multirow{2}{*}{20140718} & \multirow{2}{*}{$0.2 \mathrm{Wm}$} & 3 & 71 & 78 & 9.8 \\
& & 6 & 124 & 130 & 4.8 \\
\multirow{2}{*}{20080816} & $0.5 \mathrm{Wm}$ & 3 & 177 & 160 & 9.6 \\
& & 6 & 62 & 67 & 8.1 \\
& & 12 & 100 & 107 & 7.0 \\
20160701 & $0.5 \mathrm{Wm}$ & 6 & 146 & 133 & 8.9 \\
& & 12 & 96 & 68 & 9.3 \\
\hline
\end{tabular}

Note: $\mathrm{Wm}$ denotes the saturated soil moisture 
time are less than $15 \%$, which meets the accuracy requirements. The deviation results prove that the CR based on the RPRPC has a high reliability.

In summary, the comparison between the measured rainfall and the TRP shows that the trend characteristics of the RPRPC are reasonable. Numerical results show that the RPRPC is reasonable in terms of approach degree and CR. These results fully demonstrate that the RPRPC proposed in this paper has good reliability and can be applied to the early warning and forecasting of flash floods.

\subsection{Analysis of the Influence of the RPRPC on Critical Rainfall}

According to ASMC analysis in Xinxian, ASMC can be divided into three states: drought $(0.2 \mathrm{Wm})$, normal $(0.5 \mathrm{Wm})$ and wet $(0.8 \mathrm{Wm})$. Taking into account the current flood control capacity of Caohezu (i.e., once every 10 years), the uncertainty of the rainfall pattern and the state of the ASMC, the HEC-HMS model and the trial algorithm were used to calculate CR with different rainfall patterns and ASMCs. The corresponding calculation results for rainfall pattern and CR are shown in Fig. 7 and Fig. 8, respectively.
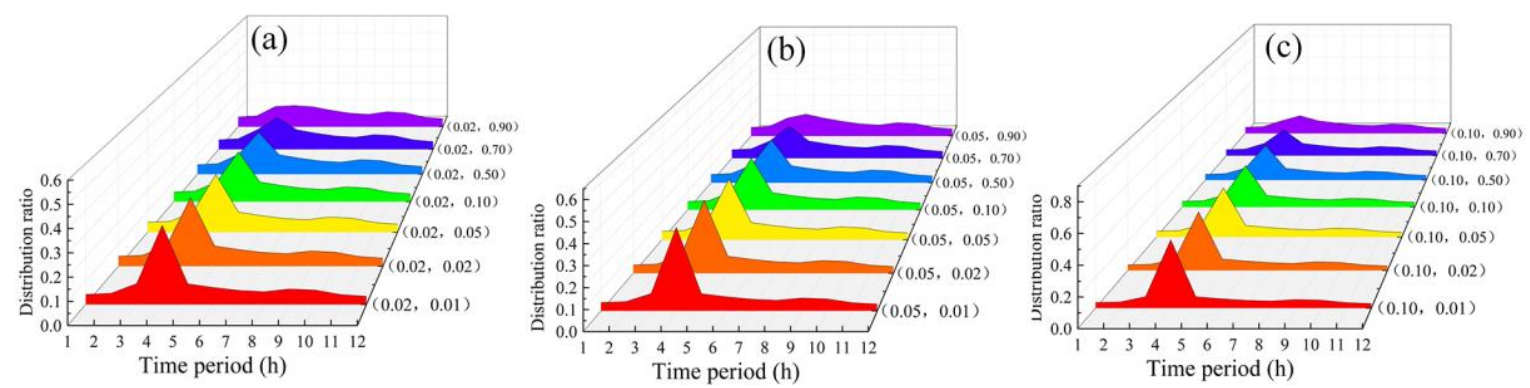

Fig. 7 Rainfall pattern collection:(a) $\left(0.02, P_{B}\right)$; (b) $\left(0.05, P_{B}\right)$; (c) $\left(0.1, P_{B}\right)$ 

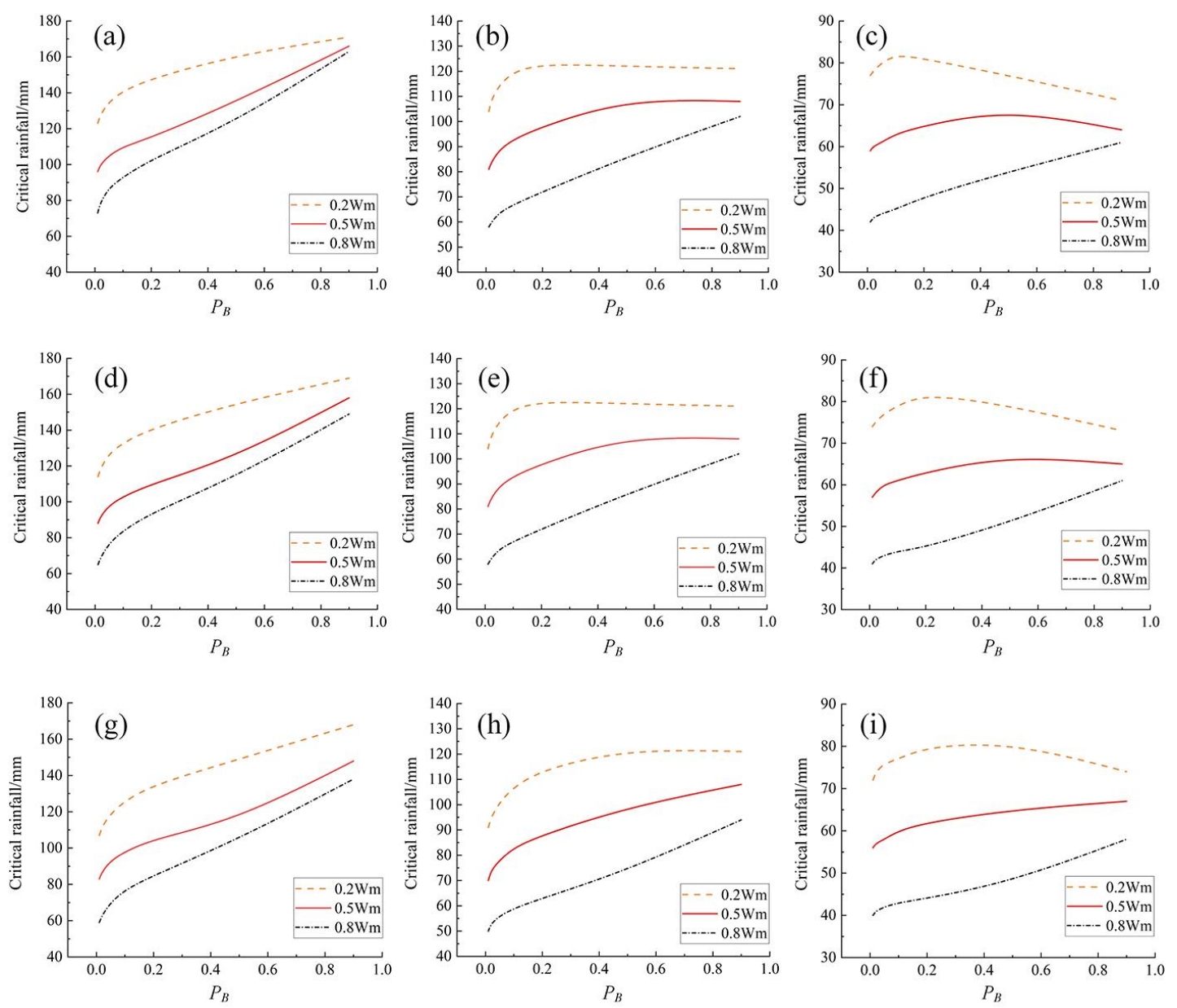

Fig. 8 Critical rainfall :(a) $P_{A}=0.02, E W T P=12$ h; (b) $P_{A}=0.02, E W T P=6$ h; (c) $P_{A}=0.02, E W T P=3$ h; (d) $P_{A}$ $=0.05$, EWTP=12 h; (e) $P_{A}=0.05$, EWTP=6 h; (f) $P_{A}=0.05$, EWTP=3 h; (g) $P_{A}=0.10$, EWTP=12 h; (h) $P_{A}$

Based on Fig. 8, the maximum CR threshold for $12 \mathrm{~h}, 6 \mathrm{~h}$, and $3 \mathrm{~h}$ are $73 \sim 163 \mathrm{~mm}, 53 \sim 101$

$\mathrm{mm}, 41 \sim 61 \mathrm{~mm}$, respectively. The corresponding CR maximum variations are $90 \mathrm{~mm}, 48 \mathrm{~mm}$, and

$20 \mathrm{~mm}$, respectively. These variations indicate that rainfall pattern has a great influence on CR.

When the risk probability of the total rainfall is constant, the CR curves for $0.2 \mathrm{Wm}, 0.5 \mathrm{Wm}$ and

$0.8 \mathrm{Wm}$ in Caohezu gradually converge with the increasing risk probability of peak rainfall intensity.

The reason for this is that the larger the risk probability of the peak rainfall intensity is, the smaller the peak rainfall intensity is. Then, the role of the rainfall peak is weakened in the whole temporal distribution of rainfall, and the rainfall pattern gradually changes to a uniform rainfall pattern, as 
brought into full play, and thus the influence of ASMC on CR is reduced. For the three EWTPs, the $\mathrm{CR}$ curves for $12 \mathrm{~h}$ are the most concentrated while the $\mathrm{CR}$ curves for $3 \mathrm{~h}$ are the most dispersed. It can be concluded that that the longer the regulation and storage time is, the smaller the influence of the ASMC on CR will be.

\subsection{Analysis of the Effectiveness for the Early Warning Mode}

The current flood control capacity of Caohezu is once every 10 years. Based on the assumption of the same frequency for rainfall and flooding, the range of risk probability combination in the study area is $\left(P_{A}<0.1, P_{B}<0.1\right)$. The corresponding O-G-P early warning mode has been calculated using the steps in Section 2.4. The results are shown in Fig. 9.

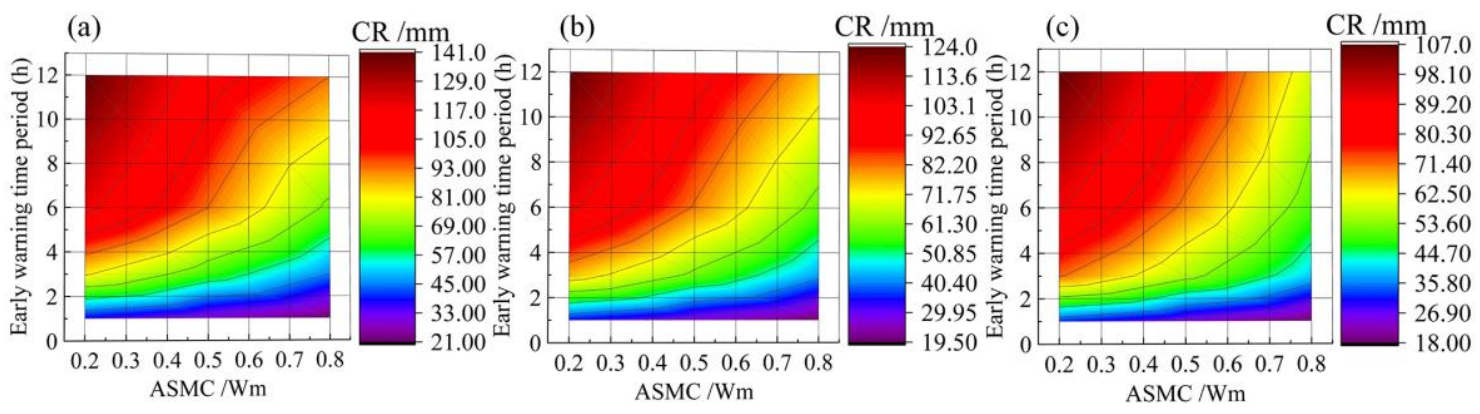

Fig. 9 (a) Optimistic early warning mode; (b) General early warning mode; (c) Pessimistic early warning mode

Rainfall 201607001 in Caohezu is taken as an example for verifying the effectiveness of the O-G-P early warning mode in the early warning of flash floods. According to the weather forecasting of the China Meteorological Agency, the rainstorm grade in Xinxian on 1st July 2016 was heavy rainfall, so the G mode was used for early warning. The ASMC for this rainfall was $0.5 \mathrm{Wm}$. The corresponding early warning information is shown in Fig. 10. 


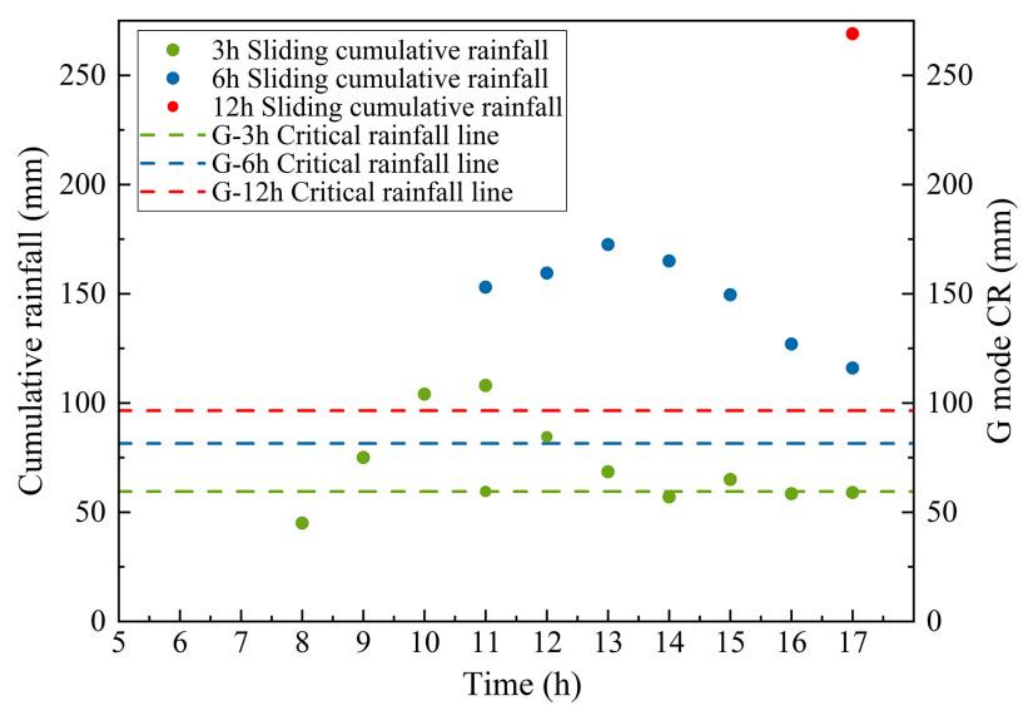

Fig. 10 Warning information chart for the G mode of Caohezu for heavy rainfall on 1th July 2016

Comparing the accumulated rainfall in various EWTPs and the CR line, the $3 \mathrm{~h}$ accumulated rainfall exceeded the G-3 CR line during the 4 th time period, and an early warning signal was issued immediately. According to the results of the flood investigation, the disaster time of formation caused by rainfall 20160701 was 10:00, and the early warning signal had been issued at 09:00 through the O-G-P early warning mode. The warning time is therefore $1 \mathrm{~h}$, which provides sufficient time for people to transfer. These results show that the O-G-P mode is effective in the early warning and forecasting of flash floods.

\section{Conclusion}

In this paper, a novel and practical rainfall pattern design method, which considers the uncertainty of rainfall pattern based on copula function, is presented through the risk probability combination of total rainfall and rainfall peak intensity. It is then applied to calculate the critical rainfall of flash floods, combined with the HEC-HMS hydrological model and trial algorithm. Through the combination of RPRPCs and ASMCs, the critical rainfall threshold space was obtained.

On this basis, an O-G-P early warning mode considering the disaster prevention experience and risk 
preference of decision makers was developed. According to the obtained results, the main conclusions are summarized as follows.

(1) Copula function can be used to determine the joint distribution function of total rainfall and peak rainfall intensity. The RPRPC design method based on copula function is a novel and practical method. The simulated rainfall processes based on the RPRPC are more accurate than those based on the traditional rainfall pattern.

(2) The flood peak and flood volume of the watershed simulated by the HEC-HMS model are very close to the measured flood data, which proves that the simulation results of the rainfall-runoff process are reasonable and reliable. The HEC-HMS model has good performance in the simulation of flash floods in a small watershed in a hilly area.

(3) Both ASMC and rainfall pattern have an impact on CR. However, when the total rainfall in the RPRPC is constant, the decrease in peak rainfall intensity will weaken the influence of ASMC on CR. In addition, the increase of rainfall duration will also weaken the influence of ASMC on CR.

(4) The O-G-P early warning mode, which considers decision makers' experience in disaster prevention and risk preference, is effective. It can provide effective information for flash flood early warning combined with rainfall forecasting information.

It should be noted that the design method of the RPRPC proposed in this study is only applicable to the calculation of unimodal rainfall pattern, which may not cover all the possible rainfall patterns in the study area. In the future, we will study the uncertainty of multimodal rainfall patterns based on this study, thereby determining the accurate critical rainfall and further improving the accuracy of the early warning of flash floods. 


\section{Acknowledgements}

The work described in this paper was supported by National Natural Sciences Foundation of China (No.51779229) and Scientific Research Projects of Henan Province (No.202102310296).

\section{Declarations}

Funding: The work described in this paper was supported by National Natural Sciences Foundation of China (No.51779229) and Scientific Research Projects of Henan Province (No.202102310296), the recipients of both fundings was Wenlin Yuan.

Conflicts of interest: The authors have no conflicts of interest to declare that are relevant to the content of this article.

Availability of data and material: The data and material used in this paper are available.

Code availability: The software application and custom code used in this paper are available.

\section{References}

Adamovic M, Branger F, Braud I, Kralisch S (2016) Development of a data-driven semi-distributed hydrological model for regional scale catchments prone to Mediterranean flash floods. J Hydrol 541:173-189. https://doi.org/10.1016/j.jhydrol.2016.03.032.

Braud I, Ayral PA, Bouvier C, Branger F, Delrieu G, Le JC, Nord G, Vandervaere JP, Anquetin S, Adamovic M, Andrieu J, Batiot C, Boudevillain B, Brunet P, Carreau J, Confoland A, DidonLescot JF, Domergue JM, Douvinet J, Dramais G, Freydier R, Gérard S, Huza J, Leblois E, Le OB, Le RB, Marchand P, Martin P, Nottale L, Patris N, Renard B, Seidel JL, Taupin JD, Vannier 

O, Vincendon B, Wijbrans A (2014) Multi-scale hydrometeorological observation and modelling for flash flood understanding. Hydrol. Earth Syst Sci 18:3733-3761. https://doi.org/10.5194/hess-18-3733-2014.

Carreau J, Bouvier C (2016) Multivariate density model comparison for multi-site flood-risk 

825. https://doi.org/10.1016/j.proeng.2016.07.413.

Gaume E, Bain V, Bernardara P, Newinger O, Barbuc M, Bateman A, Blaskovicova L, Bloschl G, Borga M, Dumitrescu A, Daliakopoulos I, Garcia J, Irimescu A, Kohnova S, Koutroulis A, Marchi L, Matreata S, Medina V, Preciso E, Sempere-Torres D, Stancalie G, Szolgay J, Tsanis

I, Velasco D, Viglione A (2009) A compilation of data on European flash floods. J Hydrol 367:70-78. https://doi.org/10.1016/j.jhydrol.2008.12.028.

Han LF, Xu YP, Pan GB, Deng XJ, Hu CS, Xu HL, Shi HY (2015) Changing properties of precipitation extremes in the urban areas, Yangtze River Delta, China, during 1957-2013. Nat Hazards 79:437-454. https://doi.org/10.1007/s11069-015-1850-3.

Hapuarachchi HAP, Wang QJ, Pagano TC (2011) A review of advances in flash flood forecasting. Hydrol Process 25:2771-2784. https://doi.org/10.1002/hyp.8040.

Hosseini FS, Choubin B, Mosavi A, Nabipour N, Shamshirband S, Darabi H, Haghighi AT (2020) Flash-flood hazard assessment using ensembles and Bayesian-based machine learning models: Application of the simulated annealing feature selection method. Sci Total Environ 711:135161. https://doi.org/10.1016/j.scitotenv.2019.135161.

Hou JM, Guo KH, Wang ZL, Jing HX, Li DL (2017) Numerical simulation of design storm pattern effects on urban flood inundation. Advances in Water Science 28:820-828. https://doi.org/ 10.14042/j.cnki.32.1309.2017.06.003.

Ivanescu V, Drobot R (2016) Deriving rain threshold for early warning based on a coupled hydrological-hydraulic model. Mathematical Modelling in Civil Engineering 12:10-21. https://doi.org/10.1515/mmce-2016-0014 
Jain SK, Sudheer KP(2008). Fitting of hydrologic models: A close look at the Nash-Sutcliffe index. J Hydrol Eng 13:981-986. https://doi.org/10.1061/(ASCE)1084-0699(2008)13:10 (981).

Kao SC, Govindaraju RS (2010) A copula-based joint deficit index for droughts. J Hydrol 380:121134. https://doi.org/10.1016/j.jhydrol.2009.10.029.

Karbasi M, Shokoohi A, Saghafian B (2018) Loss of life estimation due to flash floods in residential areas using a regional model. Water Resour Manag 32:4575-4589. https://doi.org/10.1007/s 11269-018-2071-9.

Keifer CJ, Chu HH (1957) Synthetic storm pattern for drainage design. Journal of the Hydraulics Division ASCE 83:1-25.

Klongvessa P, Lu MJ, Chotpantarat S (2018) Response of the flood peak to the spatial distribution of rainfall in the Yom River basin, Thailand. Stoch Environ Res Risk Assess 32:2871-2887. https://doi.org/10.1007/s00477-018-1603-4

Kong FZ, Huang W, Wang ZL, Song XM (2020) Effect of unit hydrographs and rainfall hyetographs on critical rainfall estimates of flash flood. Adv Meteorol 2020:2801963. https://doi.org/ $10.1155 / 2020 / 2801963$

Kuo HL, Lin GW, Chen CW, Saito H, Lin CW, Chen H, Chao WA (2018) Evaluating critical rainfall conditions for large-scale landslides by detecting event times from seismic records. Nat Hazards Earth Syst Sci 18:2877-2891. https://doi.org/10.5194/nhess-18-2877-2018.

Laouacheria F, Mansouri R (2015) Comparison of WBNM and HEC-HMS for Runoff Hydrograph Prediction in a Small Urban Catchment. Water Resour Manag 29:2485-2501. https://doi.org/ $10.1007 / \mathrm{s} 11269-015-0953-7$.

Lin GF, Chen LH, Kao SC (2005) Development of regional design hyetographs. Hydrol Process 
Liu MQ (2019) Study on rainfall early warning model of mountain flash flood based on characteristic rainfall patterns. Dissertation. School of Water Conservancy Engineering, Zhengzhou University.

Liu YY, Wang Y, Liu HW, Du LG, Liu S, Chai FX (2019) Study on Temporal Distribution of Precipitation in Beijing City during Flood Period Based on Dynamic. Journal of China Hydrology 39:74-77.

Máca P, Torfs P (2009) The influence of temporal rainfall distribution in the flood runoff modelling. Soil \& Water Res 4:S102-S110. https://doi.org/10.17221/471-SWR.

Marc O, Stumpf A, Malet JP, Gosset M, Uchida T, Chiang SH (2020) Initial insights from a global database of rainfall-induced landslide inventories: the weak influence of slope and strong influence of total storm rainfall. Earth Surf Dyn 6:903-922. https://doi.org/10.51 94/esurf-6903-2018.

Ministry of Water Resources PRC (2020) The State Council Information Office held a press conference on flood and drought disaster prevention. The State Council Information Office, PRC http://www.gov.cn/xinwen/2020-06/11/content_5518663.htm

Morin E, Jacoby Y, Navon S, Bet-Halachmi E (2009) Towards flash-flood prediction in the dry Dead Sea region utilizing radar rainfall information. Adv Water Resour 32:1066-1076. https://doi.org/10.1016/j.advwatres.2008.11.011.

National Mountain Flood Prevention and Control Group (2016) Technical requirements for inspection and verification of mountain flash flood early-warning indicators. National Mountain Flood Prevention and Control Group, Beijing. 
Norbiato D, Borga M, Dinale R (2009) Flash flood warning in ungauged basins by use of the flash flood guidance and model-based runoff thresholds. Meteorol Appl 16:65-75. https://doi.org/ 10.1002/met.126.

Palynchuk BA, Guo YP (2011) A probabilistic description of rain storms incorporating peak intensities. J Hydrol 409:71-80. https://doi.org/10.1016/j.jhydrol.2011.07.040.

Park H, Chung G (2020) A nonparametric stochastic approach for disaggregation of daily to hourly rainfall using 3-Day rainfall patterns. Water 12:2306. https://doi.org/10.3390/w12 082306.

Pedrozo-Acuna A, Moreno G, Mejia-Estrada P, Paredes-Victoria P, Brena-Naranjo JA, Meza C (2017) Integrated approach to determine highway flooding and critical points of drainage. Transport Res Part D-Transport Environ 50:182-191. https://doi.org/10.1016/j.trd.2016.11.004.

Pilgrim DH, Cordery I (1975) Rainfall temporal patterns for design floods. Journal of the Hydraulics Division ASCE 101:81-95.

Saharia M, Kirstetter PE, Vergara H, Gourley JJ, Hong Y, Giroud M (2017) Mapping flash flood severity in the United States. J Hydrometeorol 18:397-411. https://doi.org/10.11 75/JHM-D16-0082.1.

Seo D, Lakhankar T, Mejia J, Cosgrove B, Khanbilvardi R (2013) Evaluation of operational national weather service gridded flash flood guidance over the Arkansas Red River basin. J Am Water Resour Assoc 49:1296-1307. https://doi.org/10.1111/jawr.12087.

Smith G (2003) Flash flood potential: determining the hydrologic response of ffmp basins to heavy rain by analyzing their physiographic characteristics. A white paper available from the NWS Colorado Basin River Forecast Center web site at http://www.cbrfc.noaa.gov/papers/ffp_w pap.pdf. 
Tao WH, Wu JH, Wang QJ (2017) Mathematical model of sediment and solute transport along slope land in different rainfall pattern conditions. Sci Rep 7:44082. https://doi.org/10.103 8/srep44082.

Thong NH, Deo RC, Mushtaq S, Kath J, Khan S (2019) Copula statistical models for analyzing stochastic dependencies of systemic drought risk and potential adaptation strategies. Stoch Environ Res Risk Assess 33:779-799. https://doi.org/10.1007/s00477-019-01662-6.

USACE-HEC (2000) Hydrologic Modeling System HEC-HMS Technical Reference Manual. US Army Corps of Engineers, Hydrologic Engineering Centre (HEC), Davis, USA.

Yuan WL, Liu MQ, Wan F (2019a) Study on the impact of rainfall pattern in small watersheds on rainfall warning index of flash flood event. Nat Hazards 97:665-682. https://doi.org/ $10.1007 / \mathrm{s} 11069-019-03666-5$.

Yuan WL, Liu MQ, Wan F (2019b) Calculation of critical rainfall for small-watershed flash floods based on the HEC-HMS hydrological model. Water Resour Manag 33:2555-2575. https://doi.org/10.1007/s11269-019-02257-0.

Zelelew DG, Langon S (2020) Selection of appropriate loss methods in HEC-HMS model and determination of the derived values of the sensitive parameters for un-gauged catchments in Northern Ethiopia. International Journal of River Basin Management 18:127-135. https://doi.org/10.1080/15715124.2019.1672701.

Zhang Y, Wang Y, Chen Y, Liang FG, Liu HP (2019) Assessment of future flash flood inundations in coastal regions under climate change scenarios-A case study of Hadahe River basin in northeastern China. Sci Total Environ 693:133550. https://doi.org/10.1016/j.scitotenv. 2019.07.356. 
606 Zoccatelli D, Borga M, Zanon F, Antonescu B, Stancalie G (2010) Which rainfall spatial 607 information for flash flood response modelling? A numerical investigation based on data from 608 the Carpathian range, Romania. J Hydrol 394:148-161. https://doi.org/10.1016/j.jhydrol.20 609 10.07.019. 


\section{Figures}
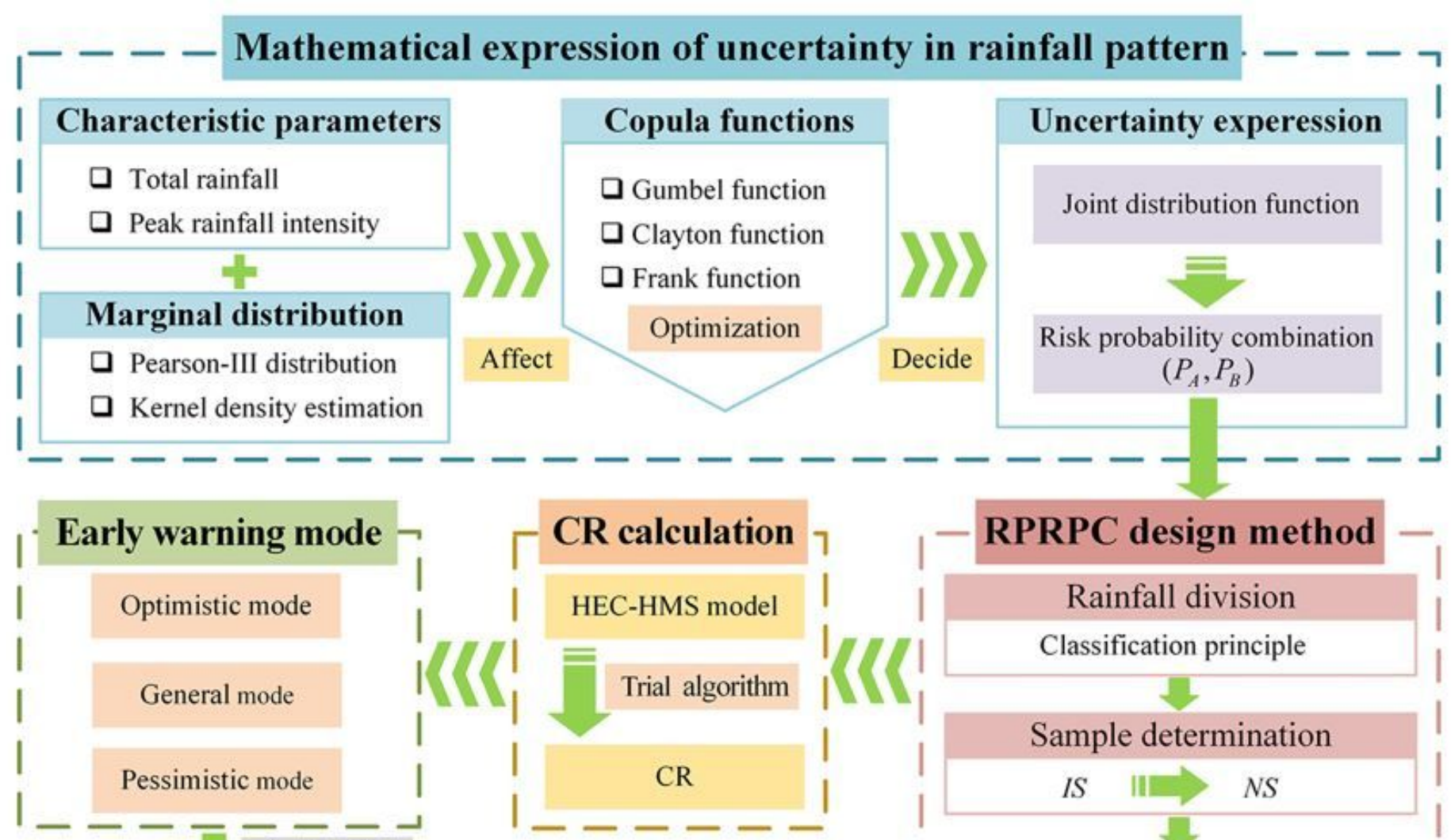

Application

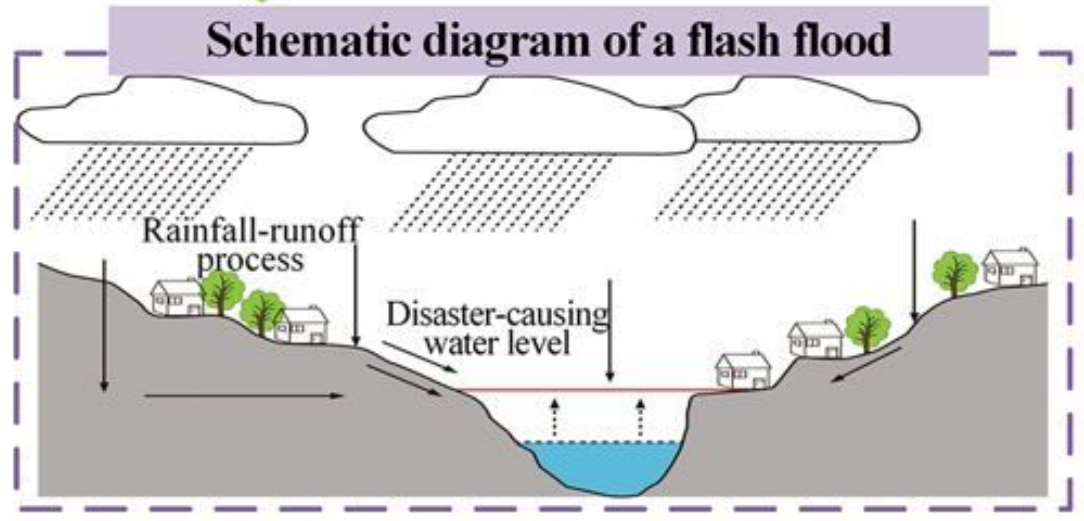

\section{RPRPC design method \\ Rainfall division \\ Classification principle}

\section{Sample determination}

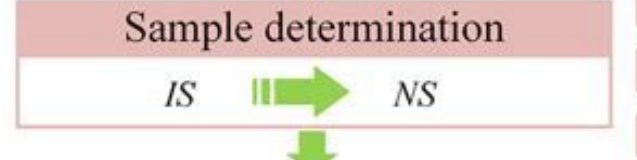

Average rainfall percentage

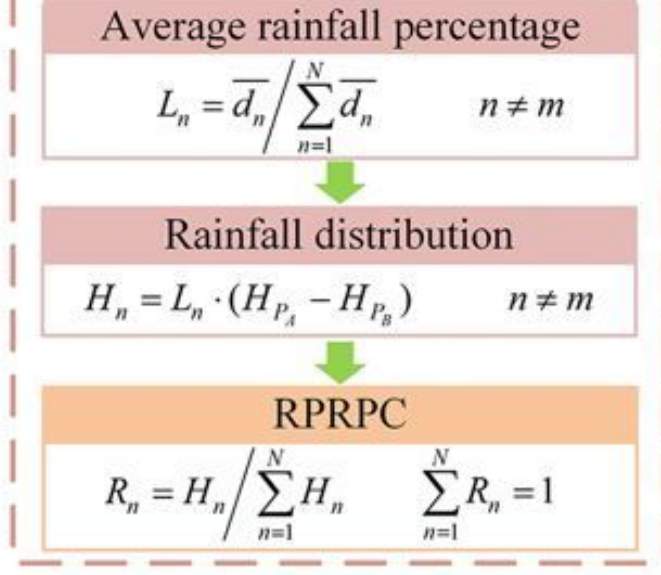

\section{Figure 1}

Schematic diagram of flash flood early warning and forecasting based on the RPRPC 


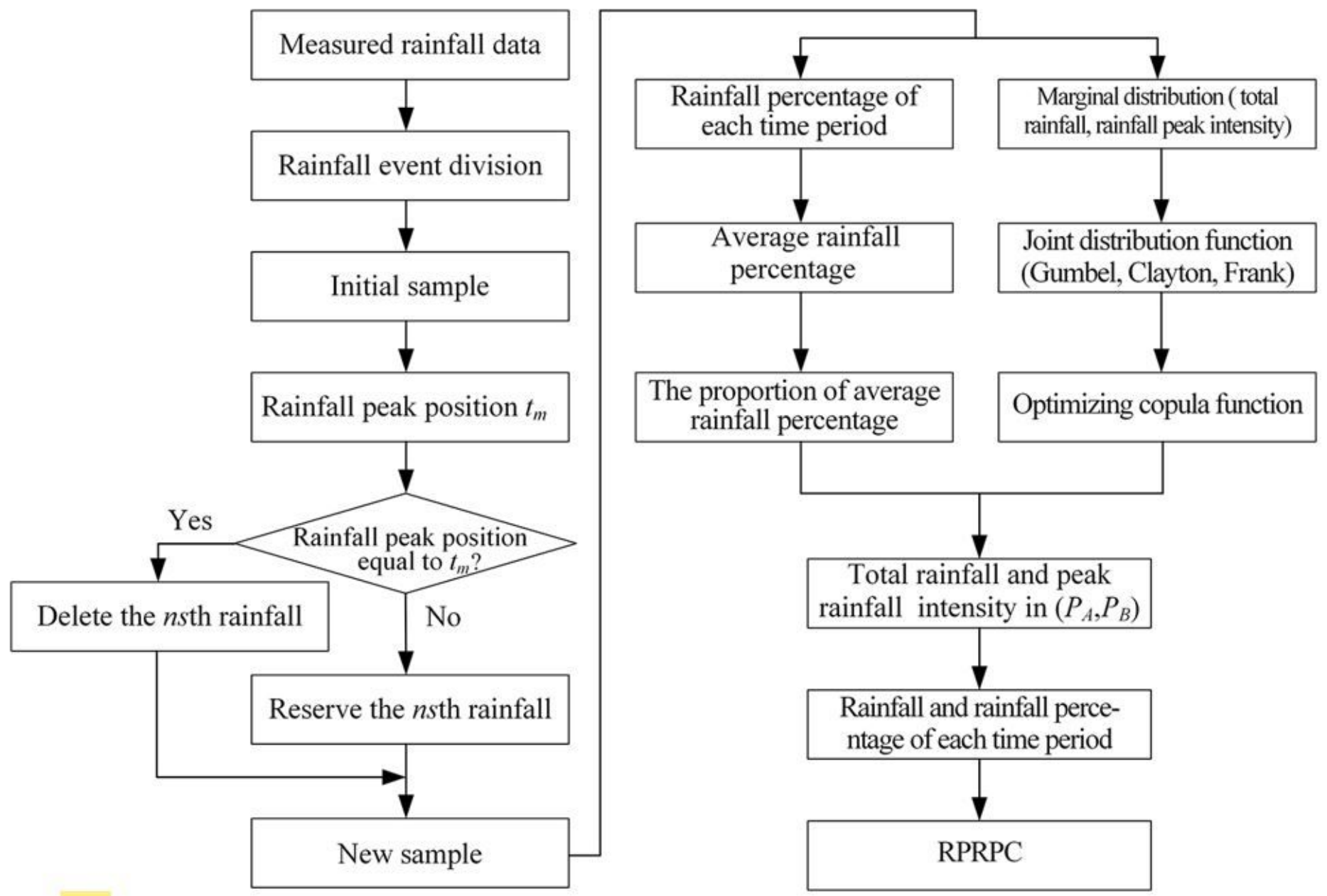

Figure 2

Calculation flow chart for the rainfall distribution for each time period 


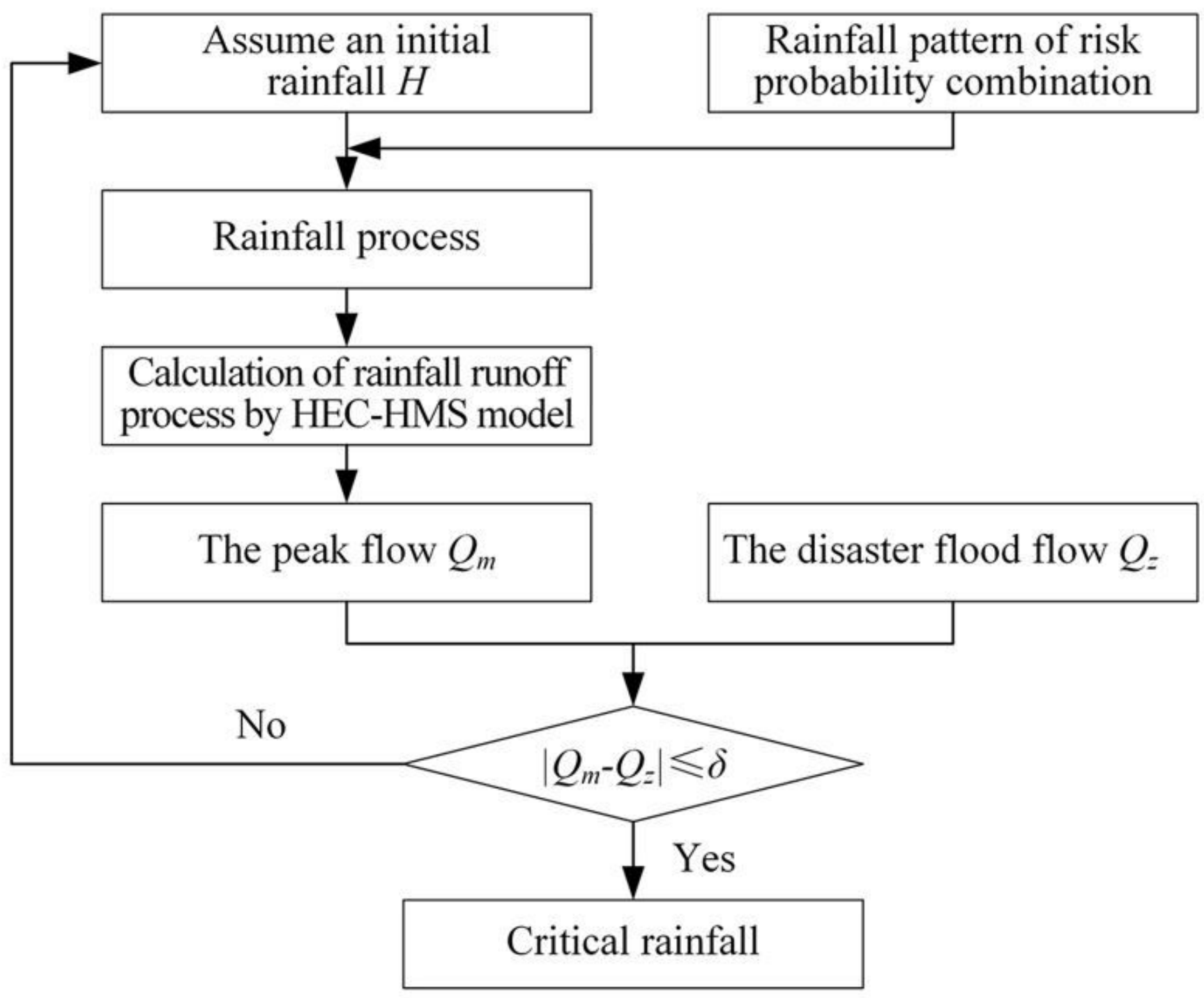

Figure 3

Flowchart of the trial algorithm for critical rainfall

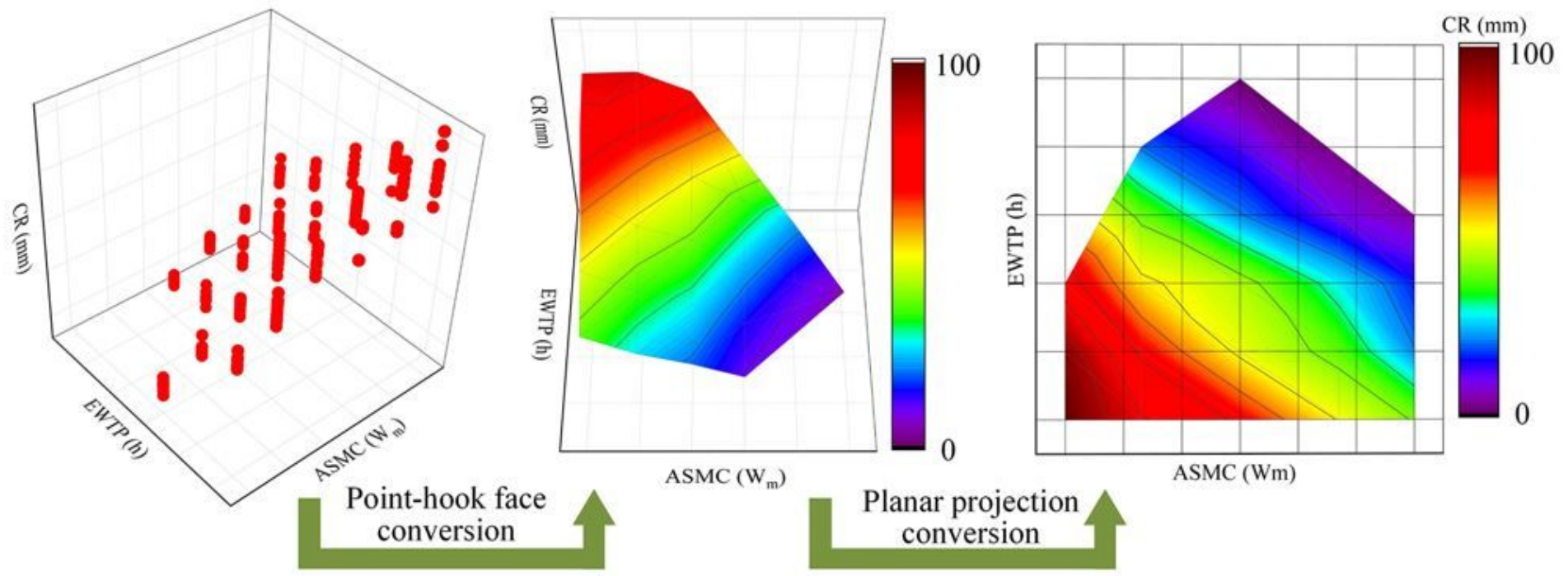


Figure 4

Schematic diagram of early warning mode establishment

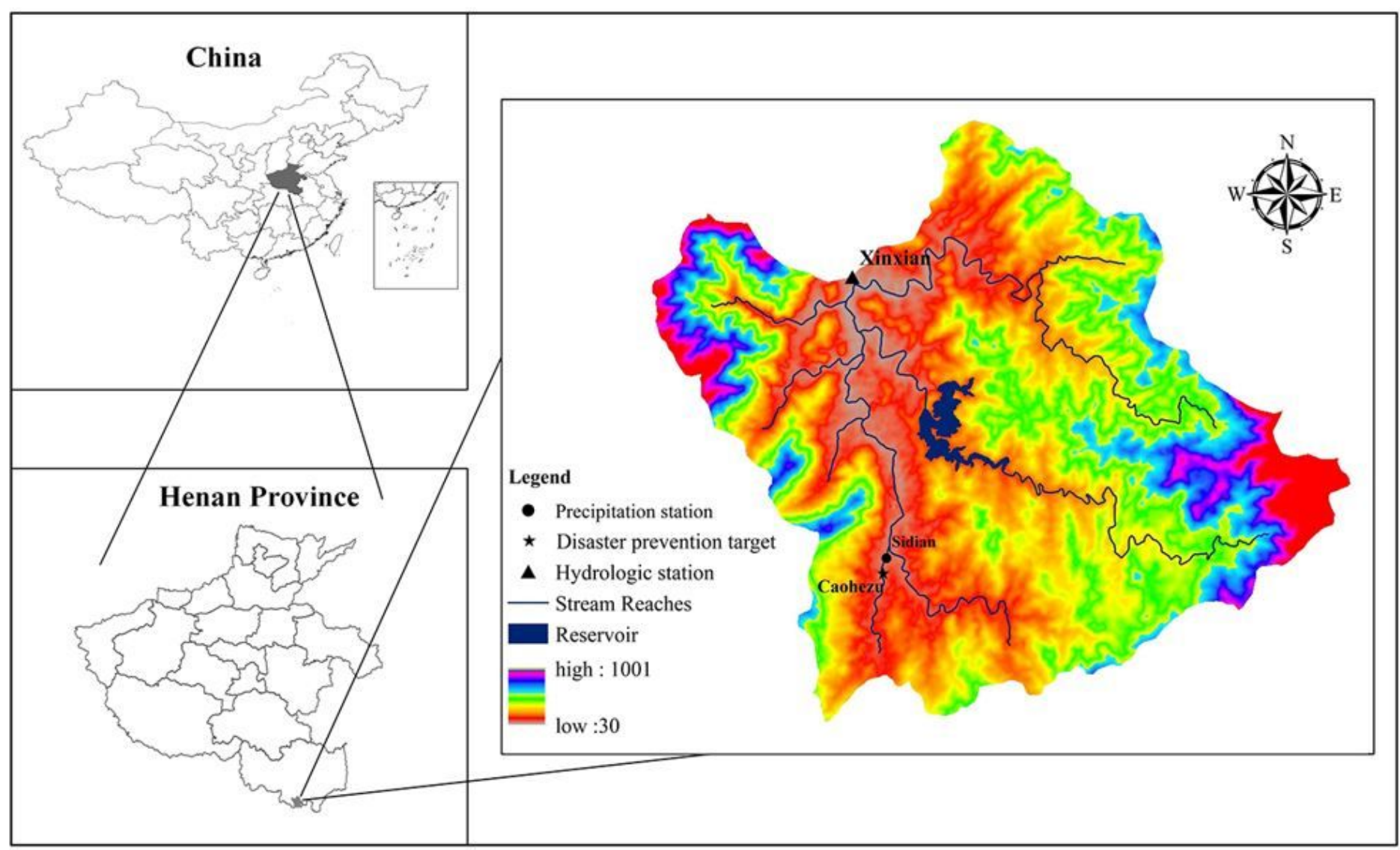

Figure 5

Schematic diagram of the Xinxian watershed Note: The designations employed and the presentation of the material on this map do not imply the expression of any opinion whatsoever on the part of Research Square concerning the legal status of any country, territory, city or area or of its authorities, or concerning the delimitation of its frontiers or boundaries. This map has been provided by the authors.
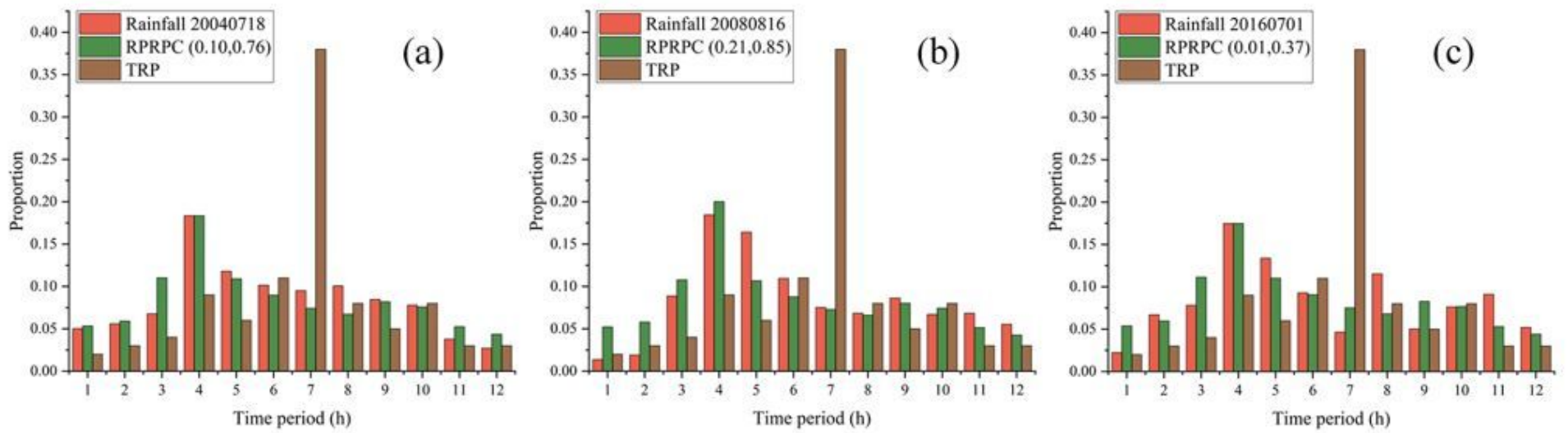

Figure 6 

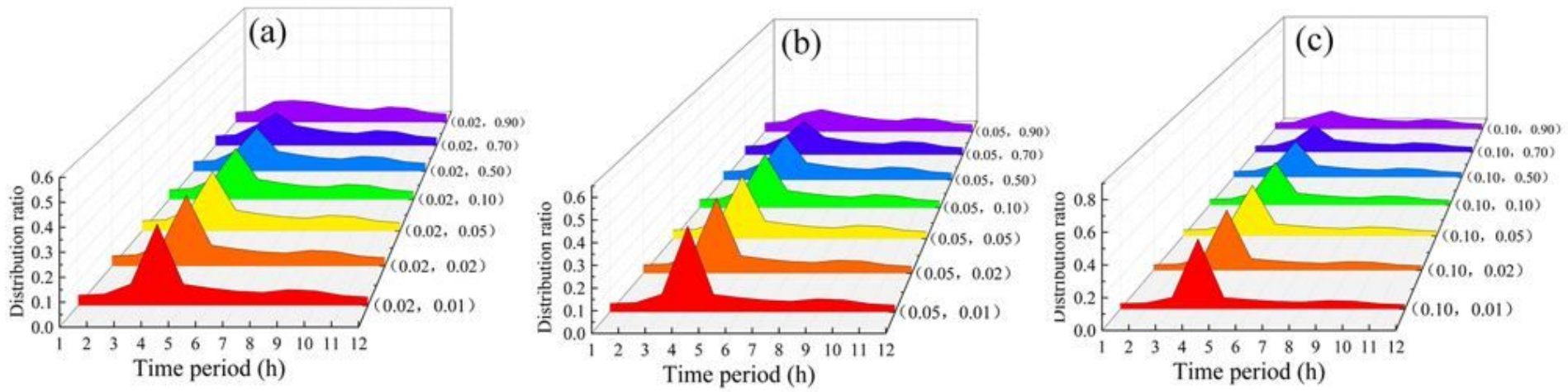

\section{Figure 7}

Rainfall pattern collection:(a) $(0.02, \mathrm{~PB})$; (b) $(0.05, \mathrm{~PB})$; (c) $(0.1, \mathrm{~PB})$
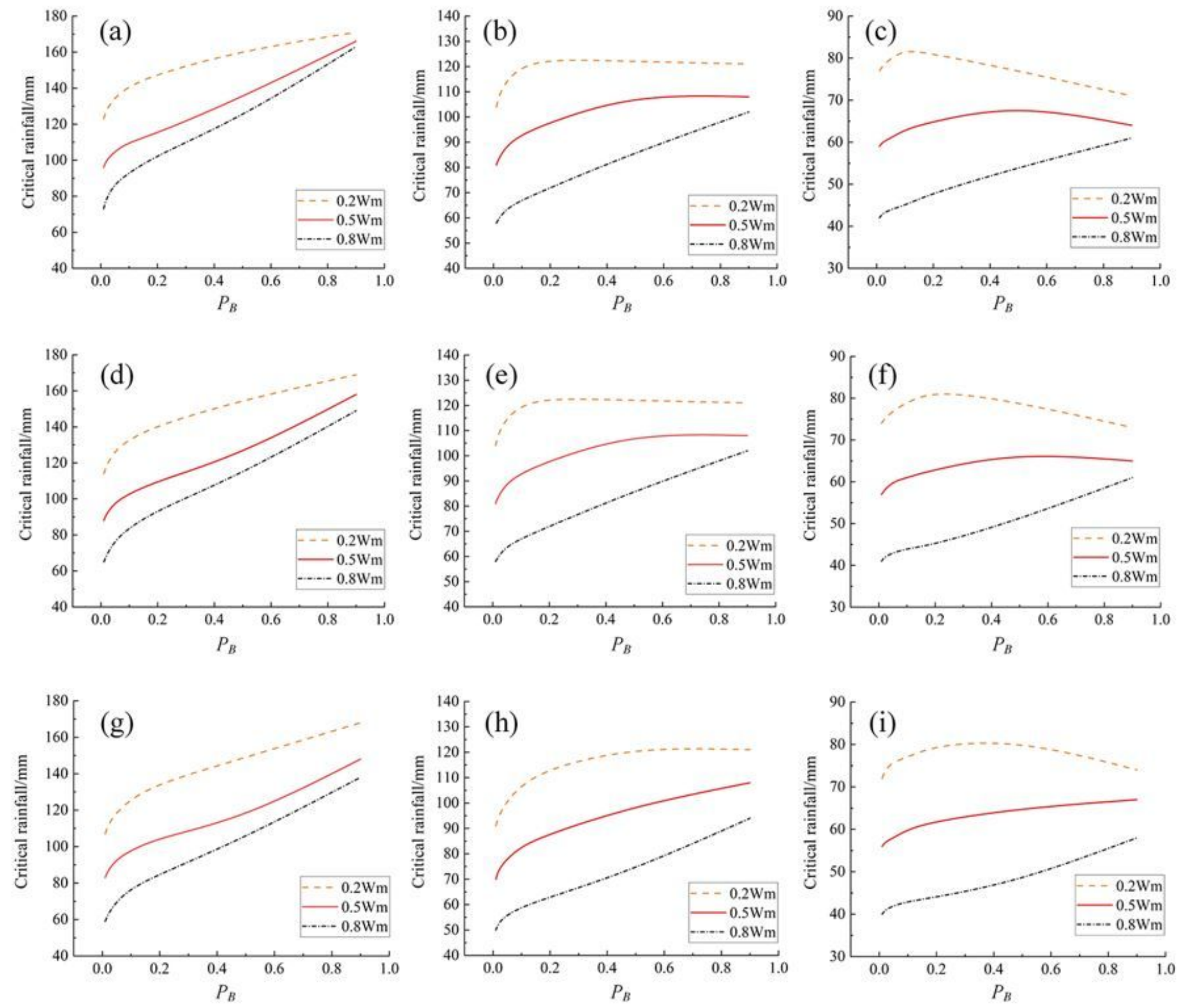


\section{Figure 8}

Critical rainfall :(a) $P A=0.02$, EWTP=12 h; (b) $P A=0.02$, EWTP=6 h; (c) $P A=0.02$, EWTP=3 h; (d) $P A=0.05$, $E W T P=12$ h; (e) PA =0.05, EWTP=6 h; (f) PA =0.05, EWTP=3 h; (g) PA =0.10, EWTP=12 h; (h) PA =0.10, $E W T P=6$ h; (i) $P A=0.10, E W T P=3 \mathrm{~h}$

(a)

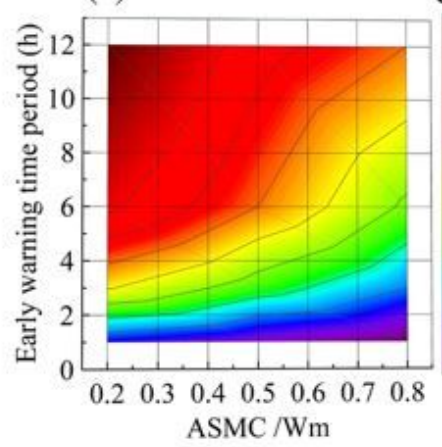

(b)

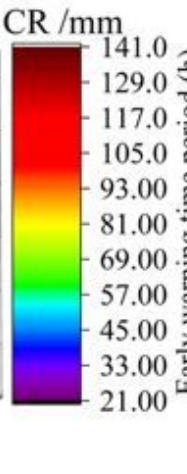

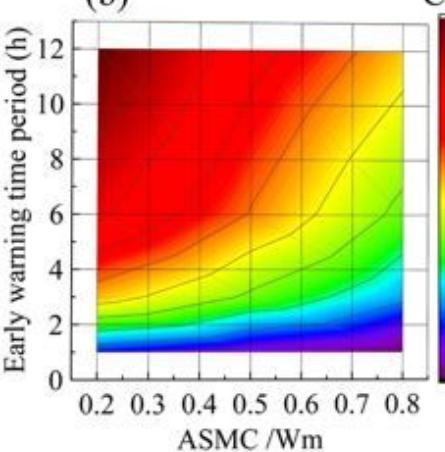

(c)

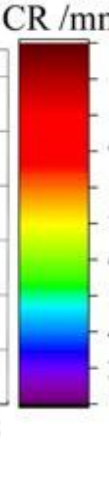

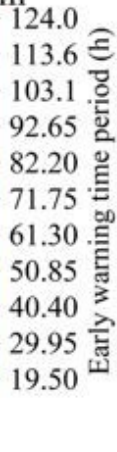

$\mathrm{CR} / \mathrm{mm}$

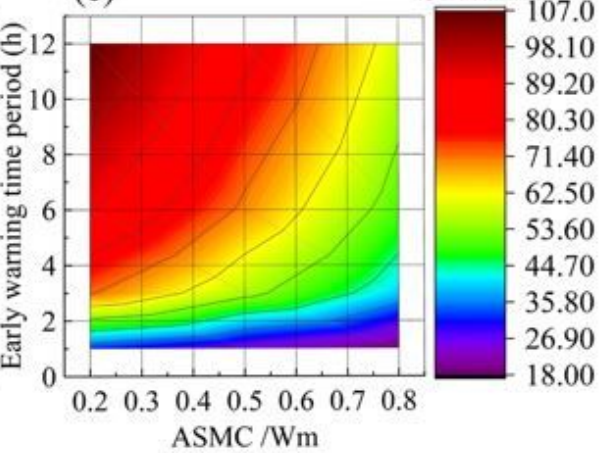

Figure 9

(a) Optimistic early warning mode; (b) General early warning mode; (c) Pessimistic early warning mode

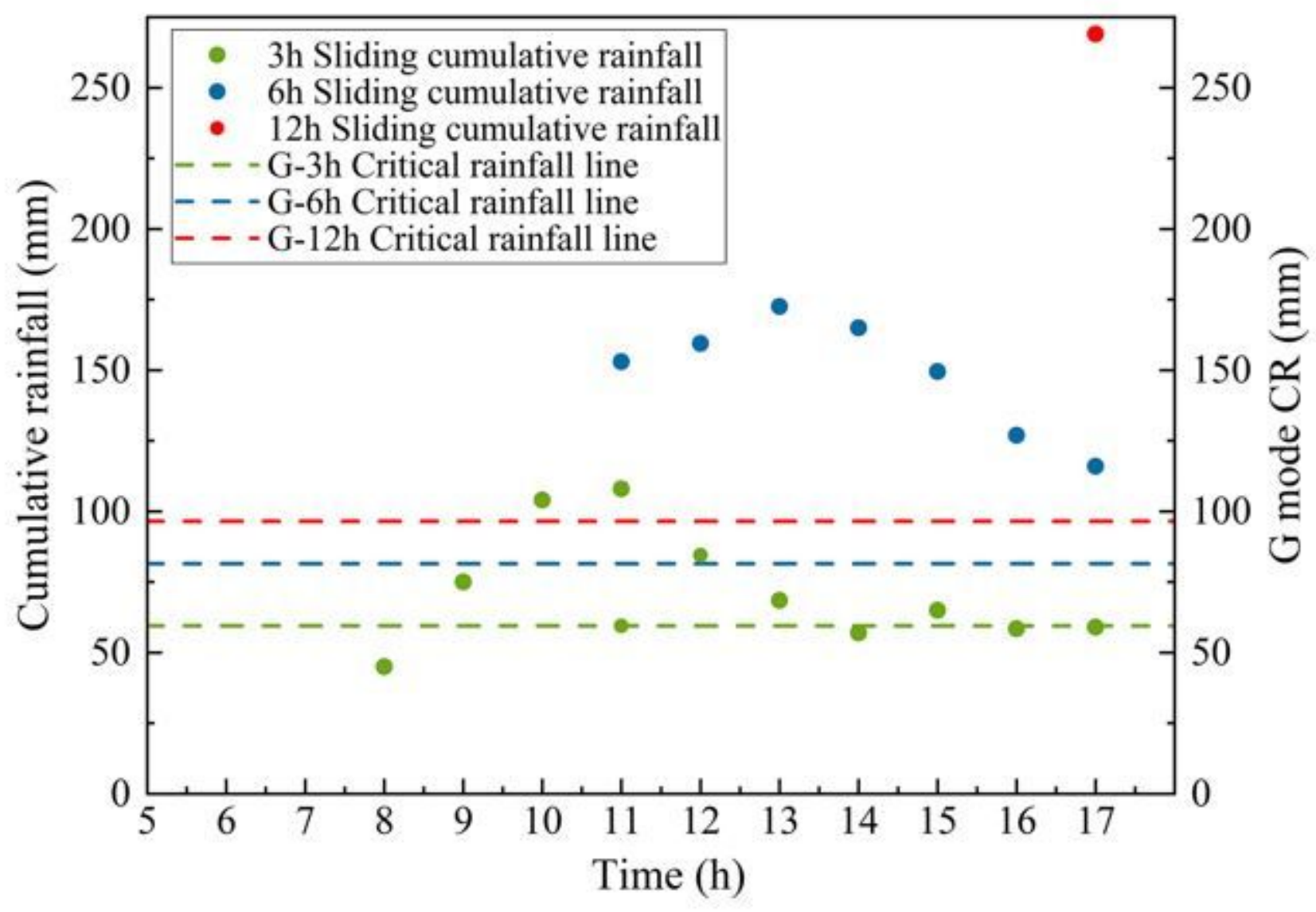

Figure 10 
Warning information chart for the $\mathrm{G}$ mode of Caohezu for heavy rainfall on 1th July 2016 